\title{
On the Persistence of Capital Structure - Reinterpreting What We Know
}

\author{
By \\ Nina Baranchuk \\ Yexiao $\mathrm{Xu}^{*}$ \\ School of Management \\ The University of Texas at Dallas
}

This version: November 2007

\begin{abstract}
Current literature has suggested that many factors affect a firm's capital structure decision and firms do not change their capital structure very often. Such a "stable" structure has prompted Lemmon, Roberts, and Zender (2007) to advocate the use of firm fixed effect in capital structure regressions. They have shown that firm fixed effect not only explains $60 \%$ of cross-sectional variation in leverage, but also crowds out all the known explanatory variables for capital structure. In this paper, we demonstrate that the popular pooled regression approach is less biased than the fixed effect model in explaining the cross-sectional variation in leverage. In other words, the crowding out phenomenon itself actually implies that the existing literature offers useful factors in understanding the capital structures dispersion. This is confirmed in our empirical study, where we find that up to $25 \%$ of the variations in the long-term mean can be explained by the known factors. Therefore, given the persistence of capital structure, we argue that it is more important to focus our attention on what determines the dynamics of capital structure. When modeling individual firms' leverage as following an $A R(1)$ process, we find that both persistence and shocks to capital structure are related to a number of firm characteristics. We also find that long-term means and persistence parameters change with business cycles. Our approach to capital structure also allows us to achieve better out-of-sample predictions for leverage.
\end{abstract}

${ }^{*}$ The address of the corresponding author is: Yexiao Xu, School Of Management, The University of Texas at Dallas, PO Box 688, Richardson, Texas 75080, USA; Email: yexiaoxu@utdallas.edu 


\title{
On the Persistence of Capital Structure - Reinterpreting What We Know
}

\begin{abstract}
Current literature has suggested that many factors affect a firm's capital structure decision and firms do not change their capital structure very often. Such a "stable" structure has prompted Lemmon, Roberts, and Zender (2007) to advocate the use of firm fixed effect in capital structure regressions. They have shown that firm fixed effect not only explains $60 \%$ of cross-sectional variation in leverage, but also crowds out all the known explanatory variables for capital structure. In this paper, we demonstrate that the popular pooled regression approach is less biased than the fixed effect model in explaining the cross-sectional variation in leverage. In other words, the crowding out phenomenon itself actually implies that the existing literature offers useful factors in understanding the capital structures dispersion. This is confirmed in our empirical study, where we find that up to $25 \%$ of the variations in the long-term mean can be explained by the known factors. Therefore, given the persistence of capital structure, we argue that it is more important to focus our attention on what determines the dynamics of capital structure. When modeling individual firms' leverage as following an $A R(1)$ process, we find that both persistence and shocks to capital structure are related to a number of firm characteristics. We also find that long-term means and persistence parameters change with business cycles. Our approach to capital structure also allows us to achieve better out-of-sample predictions for leverage.
\end{abstract}

Key Words: Capital Structure, Fixed Effect, Leverage, Persistence, Out-of-sample Prediction. 


\section{Introduction}

Great efforts have been made to understand determinants of capital structure after the seminal work by Modigliani and Miller. Although we are no where close to resolve the capital structure puzzle, we now know that many factors such as taxes, profitability, market-to-book ratio, sales, industry association, tangibility, cash flow volatility, and dividends matter. Jointly, these variables can explain about $30 \%$ of the total variation in the observed leverage ratios. However, a recent study by Lemmon, Roberts, and Zender (2007) has argued that "the value of this information may be more limited than previously thought," and thus "paint a somewhat dim picture of existing empirical models of capital structure". In particular, they believe that "capital structures are stable over long periods of time," "majority of variation in capital structure is timeinvariant," and the "existing determinants are of limited use in explaining cross-sectional variation in leverage." Using firm fixed effect in a capital structure regression, they have shown that it alone captures as much as $60 \%$ of the cross-sectional variation in leverage and almost crowds out almost all of the known capital structure determinants from the perspectives of both variance decomposition and the size of the coefficient estimates. Because they find similar results by replacing firm fixed effect with firm initial leverage, their main message calls for going "back to the beginning" to study the determinants of initial capital structure.

The empirical evidence presented in Lemmon, Roberts, and Zender, however, is more consistent with a different, and more optimistic, set of conclusions, as we discuss in detail in section 1. While we agree that leverage is persistent (as found by Flannery and Rangan (2006), Kayahan and Titman (2007) among others), it does not appear to be stable: the time series variation in leverage is $26 \%$, compared to the average level of $28 \%$. More importantly, we show in section 1 that the fixed effects regression anal- 
ysis and the portfolio analysis of Lemmon, Roberts, and Zender are likely to produce misleading results.

As a brief illustration of our argument, suppose that firm leverage $l_{t}$ fluctuates around a long-term mean $\bar{l}$, and a known factor $x$ affects the long-term mean $\bar{l}$ :

$$
\begin{aligned}
& \bar{l}=x+e_{1}, \\
& l=\bar{l}+e_{2},
\end{aligned}
$$

where $x, e_{1}$, and $e_{2}$ are independent. A fixed effects model in this context can be written as

$$
l=b_{0}+b_{1} x+b_{2} \bar{l}+u
$$

and produces $E\left(\hat{b}_{1}\right)=0$. In other words, including $\bar{l}$ in the above regression will crowd out $x$, even though by assumption, $x$ is an important determinant of leverage. In contrast, a pooled regression model omits $\bar{l}$ and produces $E\left(\hat{b}_{1}\right)=1$, which measures the true cross-sectional effect of $x$ on $l$.

The striking portfolio analysis of Lemmon, Roberts, and Zender should also be interpreted with caution due to persistence in leverage. Specifically, they find that sorting firms into portfolios using initial leverage produces portfolio leverages that slowly converge over time. We show, however, that the same result can be obtained for simulated firms whose leverages, by assumption, do not converge. We also show that sorting the same firms into portfolios based on their terminal leverage produces portfolio leverages that start from the same place but slowly diverge over time. Thus, such portfolio analysis is not informative about general trends in leverage.

Despite the potential issues, Lemmon, Roberts, and Zender (2007) has persuaded us of the importance of understanding the dynamics of capital structure. Since leverage 
is persistent, we model it using an $A R(1)$ process as a first order approximation,

$$
l_{t}=\bar{l}+\rho\left(l_{t-1}-\bar{l}\right)+e_{t},
$$

where $\bar{l}$ is the long-term leverage level. Note that this reduced form process for leverage is consistent with the common notion of leverage following a mean-reverting target. ${ }^{1}$ This model specification raises the following three types of questions:

1. what are the determinants of the long-term capital structure $\bar{l}$ ?

2. what are the determinants of leverage persistence $\rho$ ?

3. what determines stability of leverage $\operatorname{var}\left(e_{t}\right)$ ?

Note the important distinction between persistence and stability: if leverage is persistent ( $\rho$ is large), it does not mean that it has to be stable conditional on last leverage $\left(\operatorname{var}\left(e_{t}\right)\right.$ is low $)$.

While the existing literature has mainly focused on question \#1 (typically studied using pooled regressions; see Fama and French (2002), Frank and Goyal (2003), Korajczyk and Levy (2003)), we try to address all three questions directly based on the specification (1). Our focus is to evaluate to what extent the known capital structure determinants are able to address the above three questions. Thus, we restrict our choice of variables to those typically used in the literature (in particular, most of our variable definitions closely follow those in Lemmon, Roberts, and Zender). We leave identification of additional factors for future research.

\footnotetext{
${ }^{1}$ Equation (1) can be equivalently restated as

$$
\left\{\begin{array}{l}
l_{t}=l_{t}^{*}+e_{t}, \\
l_{t}^{*}=(1-\rho) \bar{l}+\rho l_{t-1}^{*}+\rho e_{t-1},
\end{array}\right.
$$
}

where $l^{*}$ is the unobservable mean-reverting target. 
We find that popular capital structure determinants have a significant explanatory power for all three parameters of the leverage dynamics: the long-term mean, persistence, and volatility. Moreover, almost all of the determinants appear as significant for both long term mean and volatility, and majority of the variables is significant for persistence. Our analysis of the long term means produces estimates of the coefficients on the leverage factors that are consistent in spirit with those found in the previous studies (direct comparison is complicated due to differences in the statistical approaches). Because we have little theory on which to base the expectations for cross sectional differences in persistence and volatility, our discussion of the estimates in the corresponding regressions is limited to our intuitive interpretation of the capital structure determinants. We find that some of the estimates are difficult to explain. In particular, it appears that firms with more tangible assets and higher net income also have more persistent leverage, which seems to contradict the usual interpretation of these parameters as indicating lower transaction costs and thus fewer constraints in the choice of capital structure. Several existing papers suggest that long term mean and persistence may change over time. Most notably, Hackbrath, Miao, and Morellec (2006) argue that in recession, target leverage ratios are higher and leverage is more persistent. We find support for both of these predictions, but we also find that the statistical model fit improves very little when business cycle indicators are included.

One significant drawback of fixed-effects panel studies is the difficulty of forming leverage predictions for firms outside the sample whose fixed effects are not yet known. We show that our analysis of the determinants of long term leverage ratios as well as persistence of leverage produces large improvements in out of sample prediction. Our model allows us to use the observed firm characteristics for forming predictions about the leverage dynamics of firms outside the sample. We show, however, that predictions are further significantly improved when the dynamics parameters are estimated directly 
from the observed leverage. This indicates the substantial amount of heterogeneity in leverage dynamics across firms.

Dynamic models of leverage that implicitly or explicitly assume that leverage is persistent are studied in a number of the existing empirical papers. Instead of estimating the target level of leverage as a parameter in a time-series model (as in our paper), many studies use capital structure determinants to construct a proxy for the target leverage (Shyam-Sunder and Myers (1999), Fama and French (2002), Korajczyk and Levy (2003), Kayahan and Titman (2007)). These studies typically aim at testing various theories of leverage and do not focus on leverage dynamics. Our analysis in section 1 cautions that this methodology may produce biased estimates of both the long term targets and coefficients on leverage factors. ${ }^{2}$

Several recent studies look at partial adjustment models of the form given by equation (1). The most relevant is Flannery and Rangan (2006), who estimate a version of equation (1) on a panel of firms, assuming that all firms have the same persistence parameter $\rho$ (or equivalently, speed of adjustment $(1-\rho)$ ). They find that the speed of adjustment is over $30 \%$, corresponding to $\rho \approx 0.7$. Because their main focus is to test the trade-off theory against the pecking order theory, they do not analyze the differences in leverage dynamics across firms and also do not try to evaluate the overall ability of the known factors to explain variations in leverage. An attempt to study the differences in dynamics of leverage across firms is offered in Drobetz and Wanzenried (2004) for a sample of 90 Swidish firms observed over a 10-year period from 1991 to 2001. Their model, however, unrealistically assumes that their leverage factors ${ }^{3}$ per- $^{-}$ fectly capture the long term leverage levels and also perfectly capture all the variation

\footnotetext{
${ }^{2}$ Substituting the estimated target with the factors used in the estimation (as done, for example, in Kayahan and Titman (2007)) does not necessarily solve the problem, as we show in section 1.

${ }^{3}$ As factors, they use four firm characteristics ((Fixed Assets)/TA, firm size, Market/Book, ROA) and four macroeconomic variables (term spread, short-term interest rate, default spread, and TED spread).
} 
in leverage persistence. This in particular implies that they cannot infer to what extent the known factors are informative about leverage dynamics parameters as well as cross sectional and time series variations in leverage.

Also relevant is the econometric analysis of models used in panel data studies of production functions and input factor productivity (for example, Griliches and Mairesse (1998), Olley and Pakes (1996), Ackerberg, Caves, and Frazer (2005)). Three strategies have been proposed-the fixed effect procedure, the instrumental variable approach, and introducing additional structure equations that backs out the unobservable factors from other observed variables. The analysis in this literature, however, cannot be directly applied in our context. Due to the different nature of endogeneity issues in capital structure analyses, the instruments suggested in the literature are not valid, but the resulting biases can be addressed in a different way, as we propose in section 2.2. Additionally, our analysis has a different goal: while the literature on production functions focuses on estimating marginal factor contributions, we are interested in studying the total contribution of capital structure factors.

This paper is organized as follows. The next section offers a statistical analysis of the estimation biases of pooled and fixed effect regression models when the same factors drive both the cross sectional and the time series changes in leverage. In addition, we also investigate the meaning of the portfolio analysis of Lemmon, Roberts, and Zender in this context. Section 2 describes our data and empirical methodology, and section 3 presents the empirical results. We conduct a number of out of sample prediction tests that help us discriminate between alternative models of leverage in section 4. Finally, section 5 offers concluding comments. 


\section{Reinterpreting Lemmon, Roberts, and Zender's (2007) Results}

Before investigating the central issue of what determines the dynamics of capital structure, we will present a simple econometric analysis that suggests a different interpretation for the empirical results of Lemmon, Roberts, and Zender (2007). Perhaps the most memorable result in Lemmon, Roberts, and Zender is captured by the figures showing a stable leverage convergence figures. We argue that these graphs could be misleading in the sense that even when individual firms' leverage fluctuates a great deal around their independent means, the sorted portfolio leverage will be perceived to converge.

\subsection{Analysis of the statistical model}

The simple model in the introduction carries most of the intuition. However, in application, leverage has both cross-sectional and time variation and also appears to be persistent. We next modify our analysis to explicitly incorporate cross sectional variation. For simplicity, we retain the assumption of no persistence. Simulation results (not reported here) show that our conclusions hold for persistent leverage as well.

For a cross-section of $N$ firms, let the $i$-th firm's leverage be $l_{i, t}$ with the unobservable

long-term mean $\bar{l}_{i}$. We generalize the model in the introduction by letting the observed factor $x_{i, t}$ capture some, but not all, of both the cross-sectional and time series variation 
in leverage: ${ }^{4}$

$$
\begin{aligned}
\bar{l}_{i} & =\gamma_{i}+\theta_{i}, \\
l_{i, t} & =\bar{l}_{i}+\eta_{i, t}+\delta_{i, t}, \\
x_{i, t} & =c \gamma_{i}+d \eta_{i, t},
\end{aligned}
$$

where $\eta_{i, t} \sim i . i . d\left(0, \sigma_{\eta}^{2}\right)$ and $\delta_{i, t} \sim i . i . d\left(0, \sigma_{\delta}^{2}\right)$ are the idiosyncratic shocks to capital structure.

Equations (2) - (4) represent a simple but general structure. In this specification, parameter $c$ captures the correlation between the observed data $x_{i, t}$ and the unobserved long-term leverage $\bar{l}_{i}$, and parameter $d$ captures the correlation between $x_{i, t}$ and the idiosyncratic shocks to leverage $\left(\eta_{i, t}+\delta_{i, t}\right)$. The observed data $x_{i, t}$, however, does not capture $\theta_{i}$ part of the cross-sectional variation and $\delta_{i, t}$ part of the time-series variation in leverage. To simplify the presentation of our results, we view $\gamma_{i}$ and $\theta_{i}$ as realizations of i.i.d. gaussian random variables with zero mean and variance $\sigma_{\gamma}^{2}$ and $\sigma_{\theta}^{2}$ respectively (this does not result in a random effects model because we still estimate each $\theta_{i}$ and $\left.\gamma_{i}\right)$

If we take the view of factor $x$ as determining the long-term leverage, we can use equations (2) - (4) to find that $\gamma_{i}=\frac{1}{c} x_{i, t}-\frac{d}{c} \eta_{i, t}$ and thus

$$
l_{i, t}=\frac{1}{c} x_{i, t}+\theta_{i}+\left(1-\frac{d}{c}\right) \eta_{i, t}+\delta_{i, t}
$$

Therefore, the true impact of $x$ on the long-term capital structure is $\frac{1}{c}$. Similarly, if we take the view of factor $x$ as determining the short-term capital structure changes, we

\footnotetext{
"Error-in-variables" is always an issue. But this is not the focus in this paper just as in Lemmon, Roberts, and Zender's (2007).
} 
use equations (2) - (4) to find that $\eta_{i, t}=\frac{1}{d} x_{i, t}-\frac{c}{d} \gamma_{i}$ and thus

$$
l_{i, t}=\frac{1}{d} x_{i, t}+\left(1-\frac{c}{d}\right) \gamma_{i}+\theta_{i}+\delta_{i, t}
$$

Therefore, the true impact of $x$ on the short-term capital structure changes is $\frac{1}{d}$.

Consistent estimation of the impact of $x$, however, cannot be achieved by either pooled or fixed effects estimation of equations (5) and (6): estimation of (5) is biased due to correlation between $x_{i, t}$ and $\eta_{i, t}$, and estimation of (6) is biased due to correlation between $x_{i, t}$ and $\gamma_{i}$. In the remainder of this section, we evaluate whether pooled or fixed effects regression produces a larger bias. We also compare the regression fit of these alternative specifications using the coefficient of determination $R^{2}$.

For notational convenience, the following analysis uses boldface for vectors created by stacking observations across firms. For example, we define $\mathbf{z}$ as follows: $\mathbf{z} \equiv\left(z_{1,1}, . ., z_{1, T}, z_{2,1}, . ., z_{2, T}, . ., z_{N, 1}, . ., z_{N, T}\right)^{\prime}$. For a regression of leverage $\mathbf{l}=\mathbf{X} b+\mathbf{u}$ where $\mathbf{X}$ is a matrix of all covariates, we let $\hat{\mathbf{u}}=\mathbf{l}-E(\hat{b}) \mathbf{X}$ and define the coefficient of determination as $R^{2}=1-E\left(\hat{\mathbf{u}}^{\prime} \hat{\mathbf{u}}\right) / E\left(\mathbf{l}^{\prime} \mathbf{l}\right)$.

\section{Case I: Pooled regression}

If we pool all the observation together, we can run the following regression:

$$
l_{i, t}=\alpha+b x_{i, t}+u_{i, t}
$$

From $O L S$ regression analysis, it is easy to show that

$$
E(\hat{b})=\frac{1}{d}[1-(c-d) \kappa]=\frac{1}{c}\left[1-(d-c) \frac{d \sigma_{\eta}^{2}}{c \sigma_{\gamma}^{2}} \kappa\right],
$$

where $\kappa=\frac{c \sigma_{\gamma}^{2}}{c^{2} \sigma_{\gamma}^{2}+d^{2} \sigma_{\eta}^{2}}$. 
In this case, the coefficient of determination $R_{\text {pooled }}^{2}$ can be computed as

$$
R_{\text {pooled }}^{2}=\frac{\sigma_{\gamma}^{2}+\left[1-\frac{(d-c)^{2}}{c} \kappa\right] \sigma_{\eta}^{2}}{\sigma_{\gamma}^{2}+\sigma_{\eta}^{2}+\sigma_{\theta}^{2}+\sigma_{\delta}^{2}} .
$$

\section{Case II: Fixed effect only}

If cross-sectional differences in firm leverage only come from unobservable firm-specific long term leverage, a fixed effects alone should capture all of the cross-sectional variation. This can be tested using the following model:

$$
l_{i, t}=\alpha_{i}+u_{i, t}
$$

Let $\mathbf{D} \equiv \mathbf{I}_{N} \otimes \boldsymbol{\nu}$, where $I_{N}$ is an N-dimensional identity matrix and $\boldsymbol{\nu}$ is a $T \times 1$ vector of ones. Then (10) can be rewritten as $\mathbf{l}=\mathbf{D} \boldsymbol{\alpha}+\mathbf{u}$, and we have the $O L S$ estimator of $\hat{\boldsymbol{\alpha}}=\frac{1}{T} \mathbf{D}^{\prime}$. Therefore, we have

$$
E\left(\hat{\alpha}_{i}\right)=\gamma_{i}+\theta_{i}
$$

In this case, $\hat{\mathbf{u}}=\mathbf{l}-E(\hat{\boldsymbol{\alpha}})=\boldsymbol{\eta} \boldsymbol{\delta}$ and the coefficient of determination can be written as

$$
R_{F E}^{2}=\frac{\sigma_{\gamma}^{2}+\sigma_{\theta}^{2}}{\sigma_{\gamma}^{2}+\sigma_{\eta}^{2}+\sigma_{\theta}^{2}+\sigma_{\delta}^{2}} .
$$

\section{Case III: both Fixed effects and factors}

The complete model is as follows,

$$
l_{i, t}=\alpha_{i}+b x_{i, t}+u_{i, t}
$$


Denoting $\mathbf{M}_{D}=\mathbf{D}\left(\mathbf{D}^{\prime} \mathbf{D}\right)^{-1} \mathbf{D}^{\prime}$, the $O L S$ estimator of $b$ is $\hat{b}=\left(\mathbf{x}^{\prime} \mathbf{M}_{D} \mathbf{x}\right)^{-1} \mathbf{x}^{\prime} \mathbf{M}_{D} \mathbf{l}$. Therefore, the $O L S$ estimators are

$$
\begin{aligned}
E(\hat{b}) & =\frac{1}{d}[1-c \kappa]=\frac{1}{c}\left[1-\left(c+(d-c) \frac{d \sigma_{\eta}^{2}}{c \sigma_{\gamma}^{2}}\right) \kappa\right] \\
E\left(\hat{\alpha}_{i}\right) & =\left[1-\frac{d \sigma_{\eta}^{2}}{\sigma_{\gamma}^{2}} \kappa\right] \gamma_{i}+\theta_{i} .
\end{aligned}
$$

The residual $\hat{\mathbf{u}}$ can be computed as $\hat{\mathbf{u}}=\mathbf{l}-E(\hat{\boldsymbol{\alpha}})-E(\hat{b}) \mathbf{x}=(c-d) \kappa \boldsymbol{\eta}+\boldsymbol{\delta}$. According to our definition of coefficient of determination, we have

$$
R_{F E x}^{2}=\frac{\sigma_{\gamma}^{2}+\sigma_{\theta}^{2}+\left[1-c^{2} \kappa^{2}\right] \sigma_{\eta}^{2}}{\sigma_{\gamma}^{2}+\sigma_{\eta}^{2}+\sigma_{\theta}^{2}+\sigma_{\delta}^{2}}
$$

\section{Comparison of the three cases}

Suppose first that the purpose is to evaluate the contribution of $x$ to the time series variation in leverage. Taking into account that the true impact is $\frac{1}{d}$, we can conclude that the pooled regression estimator derived in case I is biased downward if $x$ captures more of the cross-sectional than time series variation $(c>d)$. This implies that the numerous capital structure studies that use pooled regression analysis might be underestimating (and not overestimating as argued in Lemmon, Roberts, and Zender) the contribution of capital structure factors.

The fixed effect estimated in case II is an unbiased estimator for the long-term leverage. Adding factor $x_{i, t}$ to the fixed effect regression, however, produces a biased estimate of the factor contribution to time-series variation. Specifically, the coefficient produced in case III is biased downwards by $c \kappa$. Comparing the absolute value of the bias $|c \kappa|$ for the fixed-effects model to $|(c-d) \kappa|$ for the pooled regression, we can conclude that the fixed effects estimate is more biased when $x$ contains more crosssectional than time-series information $(c>d)$. Therefore, for the purpose of explaining 
fluctuations in leverage over time, it may still be better to use the pooled regression instead of the fixed effect regression.

Suppose next that the purpose is to evaluate the contribution of $x$ to the crosssectional variation in leverage. Taking into account that the true contribution is $\frac{1}{c}$, we can conclude that both pooled and fixed-effects estimators are biased. As before, the relative size and the direction of the bias depend on the relative size of $d$ and $c$. While the comparison of the fixed effect and pooled regression results reported in Table 5 of Lemmon, Roberts, and Zender (2007) shows that the relative bias is significant, it is difficult to conclude which of the two estimates is closer to the true value.

Some insight about the contribution of $x$ to cross-sectional and time series variation in leverage can be obtained by comparing the coefficients of determination for the three regression specifications in cases I, II, and III. Suppose that Lemmon, Roberts, and Zender are correct in concluding that $x$ has no explanatory power for the cross-section of leverage: $c=0$. Then, from equations (9), (11), and (15) we obtain

$$
R_{F E x}^{2}=R_{F E}^{2}+R_{\text {pooled }}^{2}
$$

However, according to Table 3 in Lemmon, Roberts, and Zender (2007), this relationship does not hold: they find that $R_{F E x}^{2} \approx 65 \%, R_{F E}^{2} \approx 60 \%$, and $R_{\text {pooled }}^{2} \approx 30 \%$. Therefore, $c$ cannot be zero!

Within the framework of our model, we can use these values of the coefficients of determination to assess the relative contribution of $x$ to the cross-sectional versus time-series variation if we make an additional assumption on the relative size of $\sigma_{\eta}^{2}$ to $\sigma_{\gamma}^{2}$. In order to give no advantage to either time series or cross-sectional contribution, we assume $\sigma_{\eta}^{2}=\sigma_{\gamma}^{2}$. Plugging the values into equations (9), (11), and (15), we find $d / c=0.43$, implying that the time series contribution is about twice as large as the 
cross sectional contribution. We also find that $c \kappa=0.844,\left(\sigma_{\gamma}^{2}+\sigma_{\theta}^{2}\right) /\left(\sigma_{\eta}^{2}+\sigma_{\delta}^{2}\right)=1.50$, and $\sigma_{\theta}^{2} / \sigma_{\delta}^{2}=1.88$, implying that the fixed effect model underestimates the time series contribution of $x$ by $84 \%$, while the pooled regression overestimates the contribution by $21 \%$. As for the cross-sectional contribution, fixed effect model underestimates it by $63 \%$, while the pooled regression underestimates it by $48 \%$.

\subsection{Are firms' leverage ratios converging? - An artifact of the sorting method}

Among the main findings of Lemmon, Roberts, and Zender (2007) is the steady convergence of leverage ratios over time depicted in their Figures 1 and 2. We show next, however, that a strikingly similar graph can be produced using their procedure on a sample of simulated firms whose leverage is assumed to follow an $\mathrm{AR}(1)$ process with constant long-term mean levels. This is despite the fact that, by construction, the leverage ratios of different firms in our simulated sample neither converge nor diverge over time.

We simulate annual leverage data for 200 firms $^{5}$ over 20 years using equation (1). For each firm, we first draw the persistence parameter $\rho_{i}$ from a uniform distribution $U[0.60,0.99]$. This simulation also requires us to generate the initial leverage $l_{i, 0}$ for each firm. Because we can view the initial leverage as just one observation (albeit the oldest available) of the leverage process we let the initial leverage $l_{i, 0}$ be correlated with the long-term leverage $\bar{l}_{i}$ to a certain degree:

$$
\bar{l}_{i}=\lambda l_{i, 0}+(1-\lambda) \xi_{i}
$$

where $\lambda$ captures the correlation. In our simulation, we assume $\lambda=0.2$ and draw $\xi_{i}$

\footnotetext{
${ }^{5}$ In order to see the evolution of leverage for individual firms in a graph as shown in Panel (a) of Figure 1, we only use a small number of firms.
} 
and $l_{i, 0}$ from $U[0,0.7]$. We plot each individual firms' leverage in Panel $(a)$ of Figure 1.

\section{Insert Figure 1 Approximately Here}

Panel (a) of Figure 1 shows that, although individual firms' leverage ratios are persistent, they are not converging. In fact, the cross sectional distribution of leverage remains virtually unchanged over time.

The portfolio forming procedure of Lemmon, Roberts, and Zender (2007) requires sorting firms into four portfolios according to their initial leverage $l_{i, 0}$. We plot the average portfolio leverages for our simulated firms in Panel (b) of Figure 1. Although, by construction, our simulated firms have leverage levels that are not stable and do not converge due to differences in long-term means, our graph in Panel $(b)$ is strikingly similar to Figure 1 in Lemmon, Roberts, and Zender (2007).

Interestingly, sorting firms into portfolios using their terminal (instead of initial) leverage reverses the picture, as illustrated in Panel (c) of Figure 1 using the same simulated firms. A tempting (but incorrect) interpretation of this graph would have suggested that, in contrast to Lemmon, Roberts, and Zender, firms start with the same level of leverage, and diverge over time.

Analytically, the reasons for the apparent convergence of leverage ratios in Lemmon, Roberts, and Zender portfolio analysis can be shown as follows. Consider a sample of $N$ firms where each firm's leverage is generated from (1) with long-term mean $\bar{l}_{i} \sim$ $U\left[l-\frac{d}{2}, l+\frac{d}{2}\right]$, the initial leverage $l_{i, 0}$ generated from (16), and $\xi_{i}$ drawn from $U\left[l-\frac{d}{2}, l+\frac{d}{2}\right]$. Rewriting equation (1) as the following,

$$
l_{i, t}=\rho_{i}^{t} l_{i, 0}+\left(1-\rho_{i}^{t}\right) \bar{l}_{i}+\sum_{\tau=0}^{t-1} \rho_{i}^{\tau} \epsilon_{i, t-\tau},
$$

we can conclude that the dispersion of leverage in this sample is approximately constant 
throughout the sample period, consistent with Panel $(a)$ of Figure $1 .{ }^{6}$

Consider next the portfolio forming procedure of Lemmon, Roberts, and Zender (2007) and let $\bar{l}_{0}^{\{j\}}=\frac{1}{n_{j}} \sum_{k=1}^{n_{j}} l_{j_{k}, 0}$ be the average initial leverage of the $j$-th portfolio, where $n_{j}$ is the number of firms in the $j$-th portfolio and $j_{k}$ is an index for the $k$-th firm in the $j$-th portfolio. Because the sorting is based in the initial leverage, the average initial leverage of the first two portfolios is above $l$, while that of the second two portfolios is below $l$ by construction:

$$
\bar{l}_{0}^{\{1\}}>\bar{l}_{0}^{\{2\}}>l>\bar{l}_{0}^{\{3\}}>\bar{l}_{0}^{\{4\}}
$$

First, suppose that $l_{i, 0}$ and $\bar{l}_{i}$ are uncorrelated: $\lambda=0$. Then, we can partially sum over both sides of equation (17) to obtain the $j$-th portfolio's average leverage. Because $\rho^{t} \approx 0$ for large $t$, the portfolio leverage can be approximated by

$$
\bar{l}_{t}^{\{j\}} \approx \frac{1}{n_{j}} \sum_{k=1}^{n_{j}} \bar{l}_{j_{k}}+\sum_{\tau=0}^{t-1} \rho_{j_{k}}^{\tau} \frac{1}{n_{j}} \sum_{k=1}^{n_{j}} \epsilon_{j_{k}, t-\tau} \approx l,
$$

where $l$ is the same for all portfolios $j$. Therefore, we obtain that the average leverage ratios for the four portfolios converge to the same level over time despite the assumed absence of convergence in individual firms' leverage ratios.

Next, consider a more reasonable assumption that $l_{i, 0}$ and $\bar{l}_{i}$ are positively correlated: $\lambda>0$ in equation (16). In this case, equation (19) can be revised to $\bar{l}_{t}^{\{j\}} \approx \frac{1}{n_{j}} \sum_{k=1}^{n_{j}} \bar{l}_{j_{k}}+\sum_{\tau=0}^{t-1} \rho_{j_{k}}^{\tau} \frac{1}{n_{j}} \sum_{k=1}^{n_{j}} \epsilon_{j_{k}, t-\tau} \approx \lambda \frac{1}{n_{j}} \sum_{k=1}^{n_{j}} l_{j_{k}, 0}+(1-\lambda) \frac{1}{n_{j}} \sum_{k=1}^{n_{j}} \xi_{j_{k}}=\lambda \bar{l}_{0}^{\{j\}}+(1-\lambda) l$.

Since $\bar{l}_{0}^{\{j\}}$ s are in descending order as shown in equation (18), the "converged" portfolio leverage ratios will still be in the same order after $t$ years. Thus, the average leverage

\footnotetext{
${ }^{6}$ The average sum of $n$ independent uniform variates has a bell shape distribution when $n>2$. This distribution approaches normal very quickly.
} 
ratios will not cross each other, seemingly suggesting that leverage is "stable" after 20 years despite the assumed absence of stability in individual firms' leverage ratios.

The point of our analysis in this section is to say that, if our goal is to understand why individual firms choose different levels of leverage and what prompts firms to change their leverage, we should first understand what determines the dynamic characteristics of leverage. In particular, we should ask how firms choose the long-term leverage level? What determines persistence in leverage? And, why firms deviate from their targets from time to time?

\section{Empirical Design and Data}

\subsection{Data}

We obtain our data from the monthly CRSP and quarterly and annual Compustat databases for years 1965 - 2006 (the starting date of 1965 matches that in Lemmon, Roberts and Zender). In addition to the leverage measures, we adapt the most commonly used capital structure determinants, including initial leverage, log sales, bookto-market, ROA, tangible assets, log total assets, log cash flow volatility, and dividend dummy. These variables are constructed as specified in Lemmon, Roberts and Zender (see Appendix for reference). We remove observations where either book or market leverage lies outside the closed unit interval and also remove observations where data on firm characteristics included into our analysis is missing (see the Appendix for the list and the definitions of the included variables). Our total sample contains 204904

firm-year observations and 18715 firms. For a more detailed analysis of time series dynamics of leverage, we further narrow down the sample to those firms where at least 10 years of consecutive observations is available for leverage. This leaves a sample of 7457 survived firms, 142874 firm-year observations. The summary statistics are reported in 
Table 1 for the total data set as well as for the subset of survived firms.

Insert Table 1 Approximately Here

The mean values and standard deviations of the variables closely resemble those reported in Lemmon, Roberts and Zender. For interpretation of our results, it is useful to observe that market leverage is on average $25 \%$ more volatile than book leverage. Thus, we expect our results to be generally more significant for market leverage than book leverage. In Table 1, we also report the $5^{\text {th }}$ and the $95^{\text {th }}$ percentiles and the median value for each variable. According to these statistics, both book leverage and market leverage are somewhat skewed to the right. Book-to-market and tangible asset variables also tend to be skewed to the right, while ROA is skewed to the left. The survived firms have generally similar characteristics. Most notably, they have lower book-to-market ratios and higher ROA, which suggests that market prices do reflect fundamentals. They also tend to have slightly higher average leverages.

We have argued that neither firm leverage nor portfolio leverage are stable over time in section 1.2. In order to illustrate this point, we plot the aggregate book and market leverage in Figure 2 using equal weights (Panel $(a)$ ) and value weights (Panel (b)). The vertical lines in the figure denote peaks and troughs of business cycle as identified by NBER. The graphs show that even the aggregate leverage levels change noticeably over time. The equally weighted aggregate book leverage has risen from $22 \%$ in the mid 1960 s' to $30 \%$ in the mid 1970's and gradually decreased to $20 \%$ recently as shown in Panel $(a)$ of Figure 2. The fluctuation of the equally weighted market leverage is even more pronounced and follows a similar trend. The value weighted book and market leverages depicted in Panel $(b)$, on the other hand, both exhibit a fairly consistent upward trend. Comparison of the equal and value weighted leverage ratios suggests that the decreasing trend in equally weighted leverage may be partly due to 
the increasing number of young firms going public. The difference in the patterns may also be due to the increased leverage of large firms who participated in debt-financed mergers and acquisitions. The sharp increase in leverage around 1974 observed in all graphs might be contributed to low stock prices coupled with little new equity issuance.

\section{Insert Figure 2 Approximately Here}

Figure 2 also illustrates that leverage is persistent no matter how we measure it. Therefore, it is fundamental to first understand what determines the persistence and second control for the persistence when studying interactions between the firm environment and leverage. We focus on the first issue in this paper.

\subsection{The empirical methodology}

The existing empirical evidence suggests that firms have a fairly persistent capital structure. Due to the challenge of using either pooled regression or fixed effect regression models in understanding what determines the long-term capital structure, we provide a different test strategy to separate cross-sectional factors from time-series factors. To study the time series contribution, we estimate the following base model,

$$
\text { Model } I \quad l_{i, t}=\left(x_{i, .} \phi\right)+\rho \tilde{l}_{i, t-1}+\tilde{x}_{i, t} \beta_{I}+e_{i, t},
$$

where $\tilde{l}_{i, t-1}\left(\equiv l_{i, t-1}-\bar{l}_{i}\right)$ is the demeaned leverage, $x_{i, \text {. }}$ and $\tilde{x}_{i, t}\left(\equiv x_{i, t}-x_{i, .}\right)$ are the time series mean of and the demeaned $x_{i, t}$, respectively. The coefficients $\phi$ on the time-series averages of $x$ access our ability to explain cross-sectional variation in long-term capital structure. The coefficients $\beta_{I}$ on the demeaned levels of $x$ help us understand why capital structure changes over time.

This model has the flavor of a dynamic panel model, but avoids many of the esti- 
mation issues. First, the heterogeneity in the mean is modeled explicitly with the first term in equation (21). Although this is not perfect, it substantially reduces the amount of unobserved heterogeneity, which, if left for the residuals, causes biased estimates due to implied correlation between residuals and lagged leverage. Second, the correlation between the residuals and the lagged variable is further reduced by the use of the demeaned lagged leverage instead of just lagged leverage. Finally, the heterogeneity in the mean does not change over time, the demeaned $x$ 's are unlikely to be correlated with the heterogeneity that remains in the residuals. When we further expand Model I to account for changes in the heterogeneity over time, we find little effect on the coefficient estimates. These advantages of Model I allow us to use OLS estimation method, which is more efficient that the GMM method required to produce unbiased estimates for a standard autoregressive model. Note that our Model I resembles the partial adjustment model proposed by Flannery and Rangan (2006) (they refer to $(1-\rho)$ as the speed of adjustment). Flannery and Rangan, however, used their model to evaluate leverage persistence, while we use Model I to separate time series and cross sectional variations in leverage. For a detailed study of persistence, we use a different model (Model III) as described below.

In order to understand differences in the dynamics of capital structure, we apply the following two-stage approach. In the first stage, we extend equation (1) to incorporate firm-specific coefficients allowing for cross sectional differences in leverage dynamics:

$$
\text { Model } I(a) \quad l_{i, t}=\left(1-\rho_{i}\right) \bar{l}_{i}+\rho_{i} l_{i, t-1}+e_{i, t} .
$$

Note that Model I(a) no longer includes the demeaned factors $\tilde{x}_{i, t}$. This is because of the limited amount of time series observations available for each Firm. We extend Model I(a) by including, for example, the time trend later. Since leverage data are available in both quarterly and annual frequency, equation (22) is estimated using 
both quarterly and annual data, in order to improve efficiency of estimates.

In the second stage, we use the individual estimates $\hat{\bar{l}}_{i}, \hat{\rho}_{i}$, and $\hat{\sigma}_{e}$ to run the following cross-sectional regressions:

$$
\begin{array}{cc}
\text { Model II } & \hat{\bar{l}}_{i}=x_{i, .} \beta_{I I}+\epsilon_{I I, i}, \\
\text { Model III } & \hat{\rho}_{i}=x_{i, .} \beta_{I I I}+\epsilon_{I I I, i}, \\
\text { Model IV } & \hat{\sigma}_{e i}=x_{i, .} \beta_{I V}+\epsilon_{I V, i} .
\end{array}
$$

The above Model II investigates if the existing literature offers significant insight as to what determines the long-term leverage. Model III and Model IV study what influences the dynamics of capital structure. Note that there is no "error-in-variables" problem since the estimates of $\hat{\bar{l}}_{i}, \hat{\rho}_{i}$, and $\hat{\sigma}_{e}$ are used as the dependent variables here.

Models I(a) - IV can also be estimated by substituting equations (23), (24), and (25) into equation (22). While this joint estimation procedure might lead to efficiency

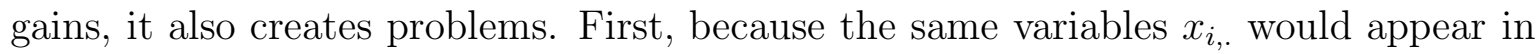
several places, multicollinearity is a concern. Alternatively, if we substituting one of the three equations above back into equation (22) to deal with the multicollinearity issue, the unsubstituted parameters will have an $i$ subscript, which leads to too many parameters to estimate when applying $M L E$. Second, equations (23), (24), and (25) all have a residual term, the direct plug-in method will introduce "error-in-variables" problem, which will bias all the estimates. Weighing bias versus efficiency, we believe it is important to avoid bias first and thus opt for the two-stage estimation procedure. 


\section{The Empirical Evidence}

We first replicate some of the analysis in Lemmon, Roberts, and Zender. Specifically, we run a pooled regression using both book and market leverage with and without controlling for the initial leverage, firm fixed effects, and year fixed effects. Table 2 reports the results for the total sample of firms and Table 3 reports the results for the subsample of the survived firms. Our results are consistent with those reported in Lemmon, Roberts, and Zender: initial leverage is strongly significant, nearly doubles the regression $R^{2}$ and crowds out some of the determinants of leverage. Firm fixed effects have a similar and even stronger impact on the regression $R^{2}$ and as well as the coefficients on the included firm characteristics.

Insert Table 2 Approximately Here

Insert Table 3 Approximately Here

\subsection{Can existing factors explain time series and cross sectional variation of leverage?}

As we discussed in section 1, the pooled regression approach provides a biased picture of the impact of firm characteristics on leverage. Instead, we use Model I given by (21) to evaluate the ability of firm characteristics to explain cross sectional and time series variations in leverage. We report the results for the estimation of Model I on the sample of 7457 survived firms in Table 4. The results are similar for both book and market leverage, so we focus our discussion on book leverage. The first column of Table 4 reports the estimates of Model I with no leverage factors $x$ included. This is our benchmark for evaluating the marginal contribution of our factors. Thus, the 
benchmark level of adjusted $R^{2}$ is $16 \% .^{7}$

\section{Insert Table 4 Approximately Here}

Including the time series means of the firm characteristics (column (3)) almost doubles the adjusted $R^{2}$, indicating a significant explanatory power of the included factors for the cross sectional variations in leverage. Because the total variation in leverage includes both time series and cross sectional variation, the results suggest that the included factors can explain more than $16 \%$ of the cross sectional variation in leverage. We take a closer look at the ability of the factors to explaining the cross sectional variation in the next section using Model I(a). The signs of the coefficients reported in column (3) coincide with those reported in Lemmon, Roberts, and Zender (their Table 2), and all of the estimates are significant. Because testing particular capital structure theories is beyond the scope of our paper, we do not discuss interpretations of the estimates; a detailed discussion can be found, for example, in Fama and French (2002) and Frank and Goyal (2004).

Comparing the estimation results in column (3) to those in column (2) (which omits $l_{t-1}-\bar{l}$ used to control for persistence) shows that including the demeaned value of the lagged leverage has virtually no effect on the ability of the factors to explain cross sectional variation in leverage. In fact, the adjusted $R^{2}$ in column (3) almost precisely equals the sum of the adjusted $R^{2}$ 's in column (1) and in column (2). Thus, the deviations of the past leverage from the long term mean are orthogonal to cross sectional variations in leverage. This supports our conjecture that the apparent significant relationship between the initial and the current leverage is due to the following endogeneity problem: both are correlated with long term mean, which is determined

\footnotetext{
${ }^{7}$ If we use the un-demeaned lag leverage variable, it is essentially a cross-sectional regression that uses mean to explain its own mean. Although this is in the same spirit as a pure fixed effect regression, it is spurious with respect to the cross-sectional explanatory power.
} 
by both observed and unobserved firm characteristics. Thus, initial leverage is unlikely to be "an economically significant determinant of future leverage" (Lemmon, Roberts, and Zender (2007, p. 31)).

Further including the demeaned values of our leverage factors into Model I results in a modest increase in the adjusted $R^{2}$ by $1.3 \%$ for book leverage and $2.4 \%$ for market leverage. All but one factor (Book/Market) are significant, and the coefficients on the demeaned factors have the same sign but much larger absolute values than the coefficients on the mean levels. Note that the increase in the adjusted $R^{2}$ provides only a lower bound on the explanatory power of the factors for the time series variation in leverage because, according to our estimates, time series variation constitutes only about one third of the total variation in leverage.

A number of papers have suggested that macroeconomic conditions may affect the optimal target leverage levels (Hackbrath, Miao, and Morellec (2006), Korajczyk and Levy (2003)). Thus, we next analyze whether their is a common time trend in long term means and whether the long term means change with business cycles, by including a time trend variable and a dummy variable for the NBER recessions. The estimation results are reported in Table 5. We find a statistically significant but economically small negative trend in both book an market leverage. We also find that during recession years, book leverage tends to increase by $0.5 \%$ and market leverage by $3 \%$, consistent with the findings of Korajczyk and Levy (2003). However, including the time trend and the business cycle dummy variables does not improve the regression explanatory power as measured by the adjusted $R^{2}$. In fact, in some cases it even reduces the adjusted $R^{2}$, indicating potential overidentification problems.

Insert Table 5 Approximately Here 
The theoretical model in Hackbrath, Miao, and Morellec (2006) also suggests that leverage persistence may change with business cycles. Specifically, persistence is expected to be lower in expansions than in recessions. Thus, we next include a product of a recession dummy and a lagged leverage into Model I. The estimation results are reported in Table 6. Our evidence supports Hackbrath, Miao, and Morellec in that the coefficient on the product is positive and significant in all regression specifications. The impact on the adjusted $R^{2}$, however, is negligible. The coefficients on the leverage factors also remain virtually unchanged.

Insert Table 6 Approximately Here

\subsection{Dynamic patterns of leverage}

In this section we study the differences in the dynamic patterns. We start by estimating firm-specific long term means, persistence coefficients and volatilities using Model I(a). Next, we test whether our firm characteristics can explain the variation across firms in these parameters using Models II, III, and IV. We can interpret the analysis of long term means as a direct analysis of cross sectional variation in leverage. It is difficult, however, to interpret the analysis of persistence or volatility as the analysis of time series variation in leverage. As an illustration, suppose we find that firm size has a positive impact on leverage volatility. Then, we can say that larger firms have less stable leverage, but cannot say what causes the upward or downward shifts in leverage.

The estimation results for Model I(a) show that there is a large variation in dynamic patterns of leverage across firms not only in long term means but also in persistence and variance of leverage. This is illustrated in Figure 3 which shows histograms of the three

parameters obtained using quarterly and annual data on the sample of 7457 survived firms. While the estimates of the long term means are the same for both quarterly 
and annual data, persistence naturally tends to be larger and volatility smaller for the quarterly data. The sample standard deviation of the long term means is about 0.15, which is twice as large as the average estimated time series standard deviation, indicating that there is substantially more cross sectional than time series variation in leverage.

\section{Insert Figure 3 Approximately Here}

For approximately twenty five hundred firms, the estimated persistence lies outside the unit circle. While the small negative or insignificant persistence is consistent with some theories of leverage (most notably pecking order theory), it is difficult to justify

persistence levels above 1. A closer examination indicates that the large values of persistence typically obtain when a company switched from having zero leverage to having a fairly large positive leverage over the course of only one or two quarters. Although such switches in policy are interesting and deserve closer examination (they are the focus of Strebulaev and Yang (2006)), they are clearly poor candidates for our model of leverage as a persistent autoregressive process. Thus, we remove the firms with persistence outside the unit interval and proceed with the analysis using the remaining 4955 firms when using book leverage and 4766 firms when using market leverage. Table 7 reports the summary statistics comparing the removed firms to those remaining in our sample. The firms removed from the sample are on average smaller, less profitable, and as expected, have lower average leverage. In fact, approximately one third of the removed observations have leverage that is zero or almost zero.

\section{Insert Table 7 Approximately Here}

For the remaining firms, we next look at the correlation between the estimated long term mean, persistence, and volatility, reported in Table 8. The correlation table 
supports our intuition that the results obtained form quarterly and annual data are similar. We find that persistence is negatively correlated with volatility, although the correlation is weak especially when looking at market leverage. This finding appears to contradict the common argument that firms with higher transaction costs (higher persistence in leverage) should wait longer before adjusting leverage (and thus have higher leverage volatility). The negative correlation in our data, however, can be consistent with the transaction costs interpretation of persistence if the transaction costs have a fixed and variable components. Firms with large variance probably face a high fixed component, and thus let the leverage deviate far from the target before taking any correcting actions. Firms with high persistence, on the other hand, face a high variable component, and thus adjust leverage in smaller amounts towards the target.

Insert Table 8 Approximately Here

We also find that long term mean is weakly positively correlated with both persistence and volatility (all correlation values are under 0.3 ). The correlation is strongest between the long term mean and volatility of market leverage. As we show later, the correlation may be due to some firm characteristics that have a similar impact on both long term mean and volatility of leverage.

\subsubsection{Long term mean}

Given persistent leverage, unbiased estimates of the impact of firm characteristics on cross sectional differences in leverage can be obtained by estimating Model II: a crosssectional regression of long-term means estimated from Model I(a) on the observed leverage determinants. We report our results in Table 9. As can be seen from the table, all of our capital structure determinants are significant and produce large $R^{2}$ 
that range between $15 \%$ and $35 \%$ depending on whether we use quarterly or annual data and whether we look at book or market leverage. As expected, the $R^{2}$ for the means inferred from the annual leverages (the bottom parts of columns 1 and 4 in Table 9 ) are higher than the $R^{2}$ for the annual leverages themselves (column (2) of Table 4). Additionally, most of the coefficients have the same sign but a larger absolute value than the coefficients obtained from the pooled regression (column (2) of Table 4).

\section{Insert Table 9 Approximately Here}

As a direct test of one of the main conclusions of Lemmon, Roberts, and Zender that firm leverages converge over time, we estimate the following regression:

$$
\text { Model } I(b) \quad l_{i, t}=\left(1-\rho_{i}\right)\left(\bar{l}_{i}+\lambda_{i} t\right)+\rho_{i} l_{i, t-1}+e_{i, t} .
$$

If Lemmon, Roberts and Zender are correct, we should see a significantly positive time trend for firms whose initial leverage is below average and a significantly negative time trend for firms with initial leverage above average.

When using annual data, we find that only $15 \%$ of the firms have a significantly positive trend, and only $12 \%$ of the firms have a significantly negative trend. The picture is similar when using quarterly data: $12 \%$ firms have a significantly positive trend and $15 \%$ have a significantly negative trend. This implies that a vast majority of firms: $73 \%$ has no statistically significant trend. Moreover, for an additional $6 \%$ of firms, the trend is not clear because the results differ for quarterly and annual data. For the remaining $12 \%$ of firms with a significant time trend, their leverage does not appear to converge, because their is virtually no relationship between their initial leverage and the estimated time trend. Specifically, the correlation between the initial leverage and the time trend is -0.025 for annual data and -0.18 for quarterly data, and both correlations are statistically insignificant. 


\subsubsection{Persistence of leverage}

While there is an extensive research that studies determinants of the level of leverage, there is little theoretical analysis of the determinants of leverage persistence. Transaction costs are often cited as responsible for persistence, but it is not clear what firm characteristics determine these costs. Several studies have suggested that macroeconomics conditions such as business cycle, underwriting costs, and changes in regulation may affect the transaction costs (for example, Leary and Roberts (2005), Hackbrath, Miao, and Morellec (2006)). These factors, however, do not help explain cross sectional differences in leverage persistence, which is the main focus of our analysis in this section. The lack of sufficiently long time series for most firms prevents us from testing whether the dynamic changes in individual firms' persistence coefficients $\rho_{i}$ are related to macroeconomic variables.

Table 9 presents the estimation results for Model III: a cross-sectional regression of the persistence coefficients $\rho_{i}$ on our leverage factors. ${ }^{8}$ Comparison of the $R^{2}$ for the results obtained using quarterly versus annual data shows that the explanatory power of the factors is more than twice as large for the annual data for both book and market leverage persistence. Although the fit is better when annual data is used for other parameters as well, the difference in $R^{2}$ is much smaller.

Among all the included factors, only ROA consistently appears as positive and strongly significant. The positive sign of the coefficient, however, is somewhat surprising because we would expect firms with larger income to have lower transaction costs and thus less persistent leverage. Also surprisingly, firm size (measured either by sales or total assets) appears insignificant in all regressions (because a large portion of

\footnotetext{
${ }^{8}$ We also looked at whether initial leverage plays a role in determining persistence and found that the two variables are not related.
} 
security flotation costs is fixed, we expected large firms to face lower transaction costs). For many of the remaining coefficients, the results differ for quarterly and annual persistence. For example, while Book/Market is insignificant for quarterly persistence, it is negative and significant for annual persistence. Dividend dummy and Industry median show the same pattern, while tangible assets are, on the other hand, significant for quarterly persistence but not annual persistence. These results, combined with the large difference in $R^{2}$ for the annual and quarterly data, indicate that different factors may be responsible for persistence in the short term and in the long term.

The negative sign of the significant coefficient on Book/Market can be interpreted as suggesting that firms with more growth opportunities have a more persistent annual leverage, consistent with the findings of Banerjee, Heshmati, and Wihlborg (2000). The positive coefficient on tangible assets is puzzling for the same reason as the positive coefficient on the ROA: tangible assets are commonly viewed as indicating financial slack, which should reduce the costs of capital structure adjustments.

\subsubsection{Time series volatility of leverage}

As for persistence, the theoretical analysis of leverage variance is scarce. In our empirical analysis of variance, we rely on Model IV: a cross-sectional regression of volatility estimated from Model I(a) on the leverage factors. The results are reported in Table 9. Despite the somewhat ad hoc selection of factors, the factors' explanatory power for volatility is large and close to that for the mean, as measured by the adjusted $R^{2}$. The direction of the effect is the same for Book/Market, ROA, and dividend dummy, but reverses for Tangible Assets and firm size, as proxied by total assets. We find that larger firms with higher ROA, more tangible assets, and firms that pay dividends have less volatile leverage, while high volatility of cash flows increases the volatility of leverage. 


\section{Out Of Sample Predictions}

In this paper we argue that auto-regressive models are more suitable for modeling leverage than pooled regressions with or without fixed effects. While the previous sections offer some support for this claim based on regression $R^{2}$ and significance of the coefficient estimates, a stronger evidence can be provided by looking at out-ofsample prediction quality. Out-of-sample prediction tests are unfortunately rare in the literature, making it difficult to conclude which models analyzed in the past are likely to offer a good fit to a new (or updated) data set. Motivated by Lemmon, Roberts, and Zender, we choose our main alternative specification as a pooled regression where initial leverage is the only determinant of future leverage.

We construct the out of sample predictions as follows. First, we randomly choose a holdout subsample of 500 firms and remove all firm-year observations on these firms from the original sample to form the estimation sample. Then, we use the estimation sample (4455 firms and 4266 firms when using book and market leverage, respectively) to re-estimate the model parameters. Finally, we use these new parameter estimates to form predictions for the 500 holdout firms and evaluate the prediction quality using the root-mean-squared-error $(R M S E)$. For our base model this means first estimating $\hat{\overline{l_{i}}}$ and $\bar{\rho}_{i}$ in Model I(a) for the estimation sample, and next using the $\bar{l}_{i}$ and $\bar{\rho}_{i}$ to fit Models II and III. We use the resulting estimates of $\beta_{I I}$ and $\beta_{I I I}$ to form predictions $\hat{\hat{\rho}_{j}}$

and $\hat{\bar{l}}_{j}$ for the 500 holdout firms using their observed firm characteristics $x$. Finally, we use the predicted values $\hat{\rho}_{j}$ and $\hat{\overline{l_{j}}}$ to form predictions $\hat{l_{j t}}$ for leverage at time $t$ based on Model I(a). We do this in the following two ways: first, we use the predicted values of leverage to form future predictions (we refer to it as Model (3)), and second, we use the realized values of leverage to form future predictions (Model (4)). For comparison, we also form predictions using the long term mean and persistence directly estimated from 
the realized leverage of the 500 hold out firms (Model (2)). For the main alternative model, Model (1), the predicted leverage simply equals the initial leverage. Note that this alternative specification is by definition better than a fixed effects pooled regression because the fixed effects estimates are not useful when forming predictions for firms outside the sample.

\section{Insert Table 10 Approximately Here}

We repeat the prediction procedure 1000 times and thus obtain a sample of 1000 $R M S E$ 's for each of the four models. The average RMSEs and the standard deviations of $R M S E \mathrm{~s}$ for the four models are reported in Table 10. The results show that even when using predicted levels of leverage and predicted dynamics parameters (Model (3)), the out-of-sample $R M S E$ beats that using the realized initial leverage when forming predictions for future leverage. The difference in the two RMSEs is moderate and statistically significant. Specifically, Model (3) improves $R M S E$ of the alternative Model (1) by $8 \%$ and $13 \%$ for book leverage and market leverage, respectively. Perhaps a more realistic Model (4), which predicts next period leverage based on the current realized leverage, produces a large improvement in $R M S E$. In particular, the mean squared error produced by Model (4) is more than $40 \%$ smaller than that produced by Model (1) for both book and market leverage. Comparing the performance of Model (4) and Model (2) (the best case scenario), we can conclude that the unexplained heterogeneity across firms in dynamics characteristics is still significant. 


\section{Concluding Comments}

Perhaps the most important characteristics of leverage is its persistence. Yet, it is not the main focus of the current literature. This may be due to our perception of persistence as "stability" in leverage. The perceived stability is probably responsible for the narrow focus of the existing research on the determinants of the long term mean. Since leverage is persistence, however, it is important to also understand what determines the speed of convergence and the variance of deviations from the long term mean.

Our statistical analysis shows that even when focusing on understanding long term mean, it is important to account for persistence in leverage. Failing to account for persistence leads to biased estimates and thus misleading conclusions about the importance of leverage determinants. We also caution against the use of such determinants as initial leverage and fixed effects. Although they can be viewed as a reasonable estimates of the long-term mean, they are not exogenous to the current leverage. We show that including such variables is equivalent to giving up the quest for capital structure determinants because coefficients on these variables tend to absorb most of the impact of valid capital structure determinants.

In order to understand the dynamic patterns of leverage, we propose a statistical model that explicitly accounts for persistence and produces unbiased estimates on capital structure determinants. We document that there is a large heterogeneity in target levels, persistence and volatility of leverage ratios across firms. We find that the existing leverage factors have a reasonably high explanatory power for cross sectional differences in target leverage ratios and volatility of leverage. They also capture some differences in persistence levels. However, a large portion of heterogeneity in persistence remains unexplained. From a practical perspective, modeling leverage persistence improves our 
ability to predict capital structure for firms outside the sample. The ability to form predictions may be useful for arbitrage-type investments and also may help firms in determining their optimal capital structure. 


\section{References}

[1] Ackerberg, Daniel A., Kevin Caves, and Garth Frazer, 2005, Structural Identification of Production Functions, working paper.

[2] Banjeree S., A. Heshmati, and C. Wihlborg, 2000, The Dynamics of Capital Structure, Working Paper No. 2000:2.

[3] Drobetz, W., Wanzenried, G., 2004, What determines the speed of adjustment to the target capital structure? Working paper, University of Basel.

[4] Griliches, Zvi, and Jacques Mairesse, 1998, Production Functions: The Search for Identification, In: Econometrics and Economic Theory in the Twentieth Century: The Ragnar Frisch Centennial Symposium, ed. S. Strøm. Cambridge, UK: Cambridge University Press.

[5] Fama, E., French, K., 2002. Testing trade-off and pecking order predictions about dividends and debt. Review of Financial Studies 15, 1Ü-34.

[6] Flannery, Mark and K Rangan, 2006, Partial adjustment toward target capital structures, Journal of Financial Economics 79 469-506.

[7] Frank, Murray Z., and Vidhan K. Goyal, 2003, Testing the pecking order theory of capital structure, Journal of Financial Economics 67, 217-Ü248.

[8] Frank, Murray Z. and Vidhan K. Goyal, 2004, Capital structure decisions: Which factors are reliably important?, Working Paper, University of British Columbia.

[9] Hackbarth, Dirk, Jianjun Miao, Erwan Morellec, 2006, Capital structure, credit risk, and macroeconomic conditions, Journal of Financial Economics 82, 519Ü550 
[10] Kayahan, Ayla, and Sheridan Titman, 2007, Firms ̌̌ histories and their capital structures, Journal of Financial Economics 83 1-Ü32.

[11] Korajczyk, Robert A., and Amnon Levy, 2003, Capital structure choice:macro economic conditions and financial constraints, Journal of Financial Economics 68, 75-Ü109.

[12] Leary and Roberts, 2005, Do Firms Rebalance Their Capital Structures?, Journal of Finance 60, 2575-2619.

[13] Lemmon, Michael L., Michael R. Roberts, and Jaime F. Zender, Back to the Beginning: Persistence and the Cross-Section of Corporate Capital Structure, The Journal of Finance, forthcoming.

[14] Olley, Steve and Ariel Pakes, 1996, The Dynamics of Productivity in the Telecommunications Equipment Industry, Econometrica 64, 1263-1295

[15] Shyam-Sunder, Lakshmi, and Stewart C. Myers, 1999, Testing static tradeod' against pecking order models of capital structure, Journal of Financial Economics $51,219-244$.

[16] Strebulaev and Yang, 2006, The Mystery of Zero-Leverage Firms, working paper. 


\section{Appendix A: Variable Definitions}

Below is the list of variable definitions used in our analysis. All of the variable definitions are are taken from Lemmon, Roberts, and Zender. All numbers in parentheses refer to the annual Compustat item number.

Total Debt $=$ short term debt $(34)+$ long term debt $(9)$.

Book Leverage $=$ total debt / book assets (6).

Firm Size $=\log ($ book assets $)$, where assets are deflated by the GDP-deflator.

Profitability $(\mathrm{ROA})=$ operating income before depreciation (13) / book assets.

Cash Flow Volatility $=$ the standard deviation of historical operating income requiring at least three years of data.

Market Equity $=$ Stock Price (199) * Shares Outstanding (54).

Market Leverage $=$ Total Debt / $($ Total Debt + Market Equity $)$.

Market-to-Book $=($ market equity + total debt + preferred stock liquidating value $(10)$

- deferred taxes and investment tax credits (35)) / book assets.

Initial Leverage $=$ First nonmissing value for Book (or Market) Leverage for a firm . Tangibility $=$ net PPE / book assets. 

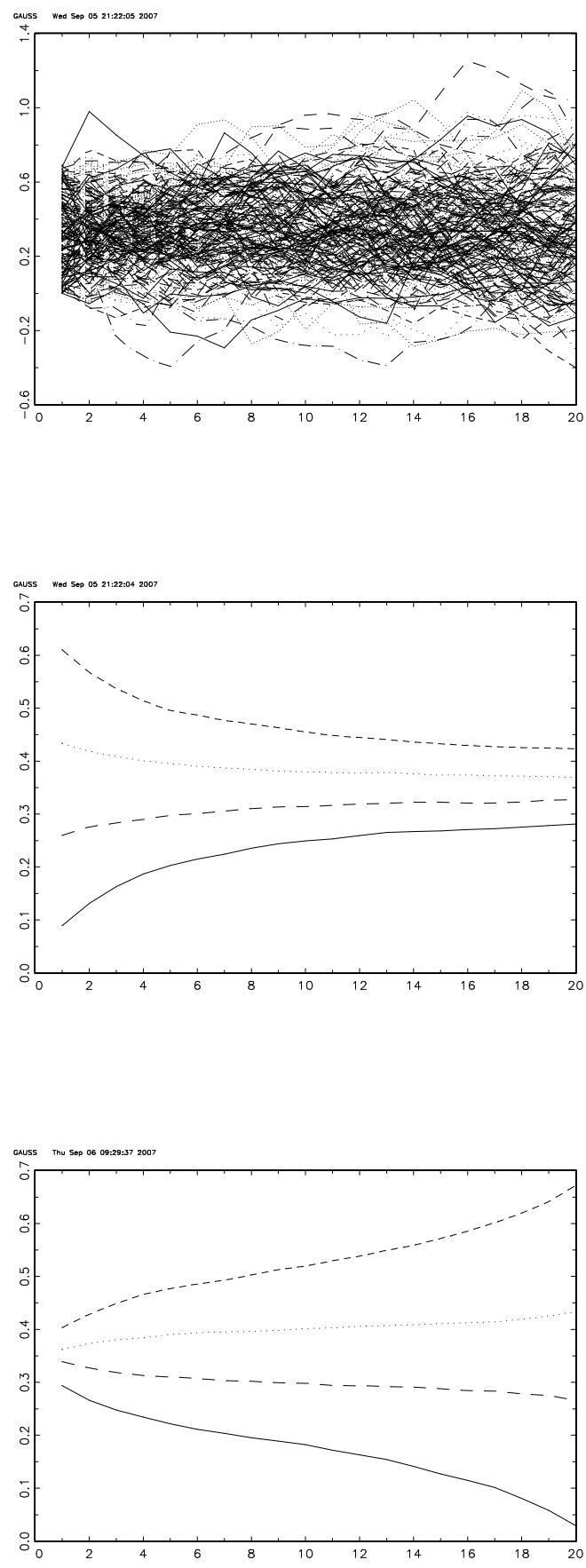

Figure 1: Leverage over time: (a) $\hat{\bar{l}}$ Firm level leverage. (b) Portfolios sorted on initial leverage. (c) Portfolios sorted on terminal leverage. 
Panel [a] Aggregate Leverage with Equal Weight [1965-2006]

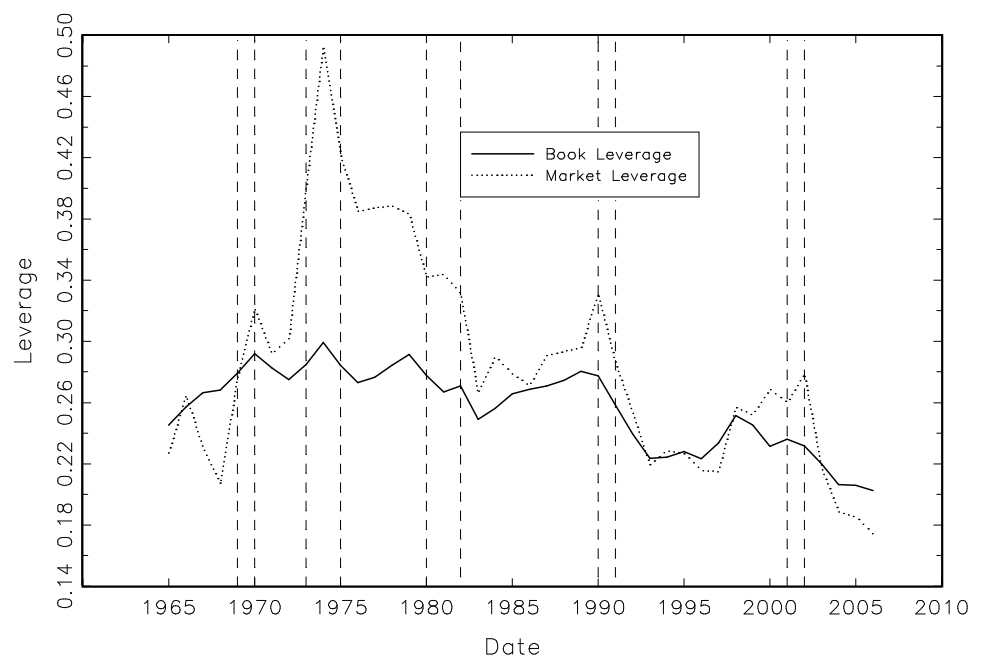

Panel [b] Aggregate Leverage with Value Weight [1965-2006]

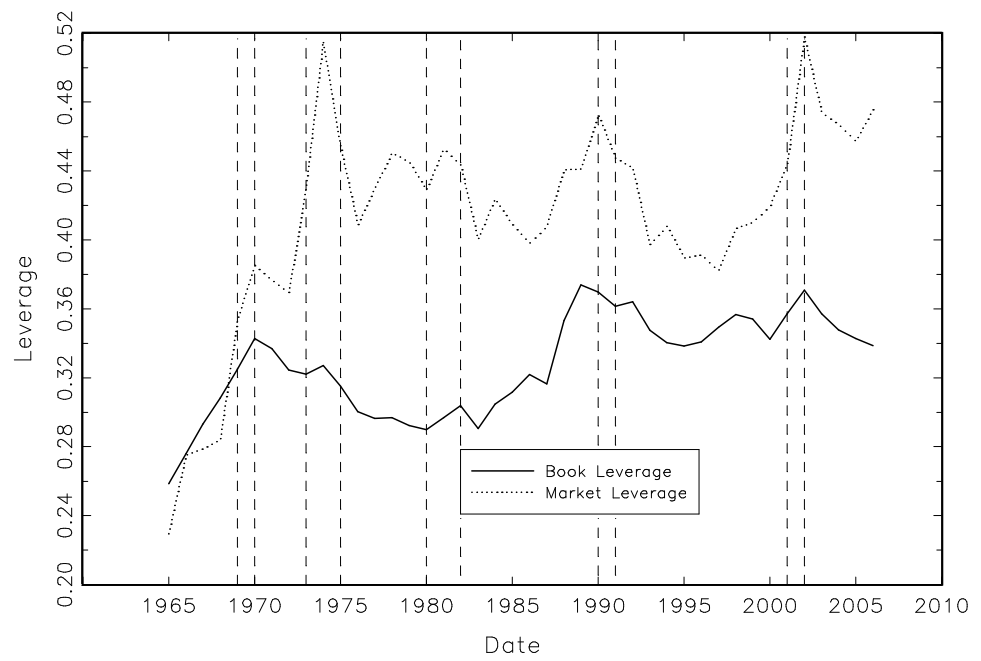

Figure 2: Aggregate Leverage From 1964-2006: (a) Equal weighted leverage. (b) Value weighted leverage. 

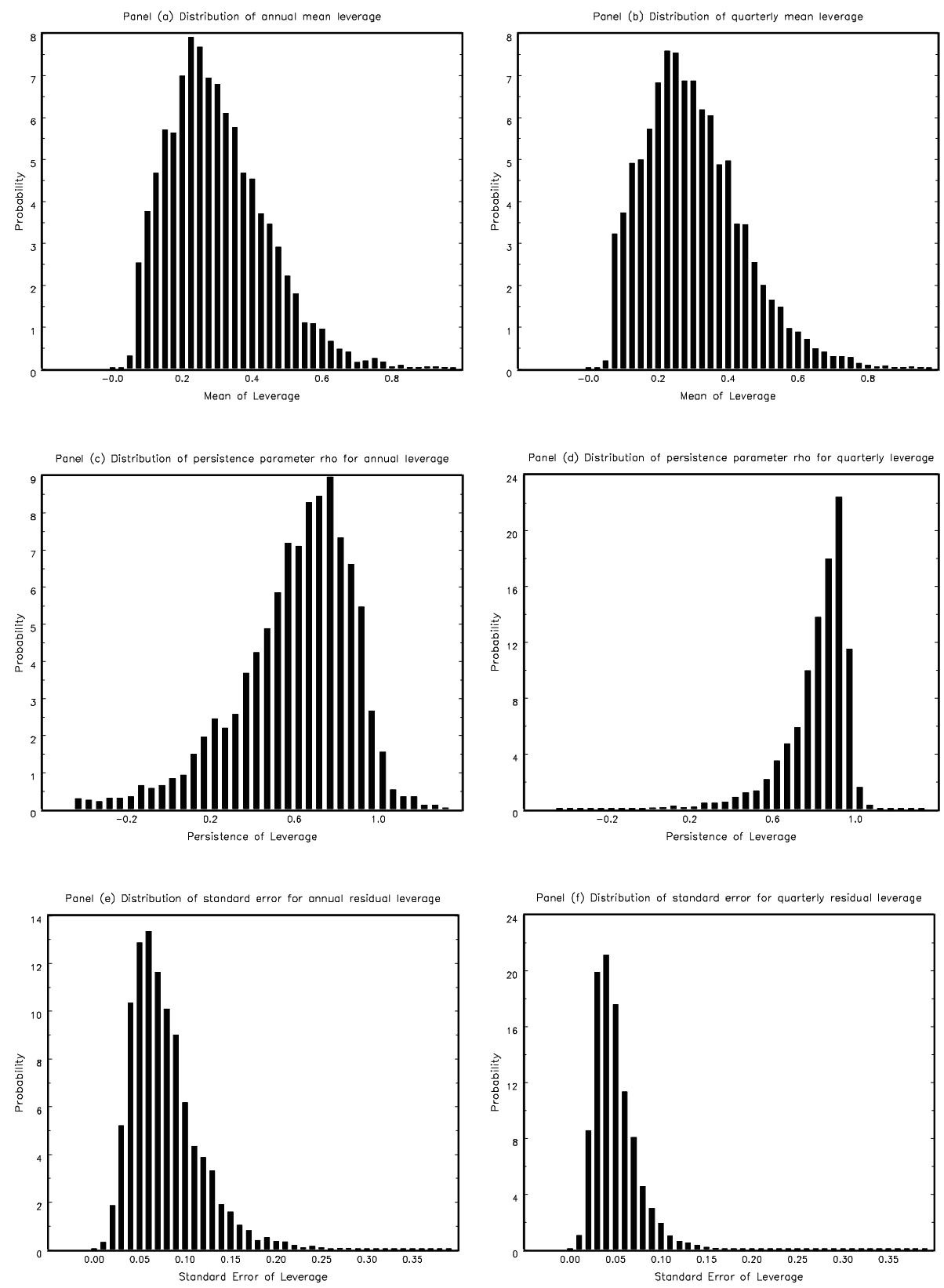

Figure 3: Distributions of the Parameters of an AR(1) Model Fit to Book Leverage From 1964-2006: (a) $\bar{l}$ from annual leverage; (b) $\bar{l}$ from Quarterly leverage; (c) $\rho$ from annual leverage; (d) $\rho$ from Quarterly leverage; (e) $\sigma$ from annual leverage; and (f) $\sigma$ from Quarterly leverage. 


\section{Table 1: Descriptive Statistics for All Variables}

This table reports the descriptive statistics for both leverage variables and each of the determinants. The data set contains 18597 firms from 1965 to 2006 reported in COMPUSTAT. Under "All Firms," we include firms with non-missing data for both leverages and determinants in a year. The "Survived firms" are in the subsample of firms required to have at least 10 years of consecutive records. " $5 \%$ " and $95 \%$ " represents the lower and upper $5 \%$ percentile, respectively. Variable definition can be found in the Appendix.

\begin{tabular}{l|ccccc|ccccc}
\hline \hline \multirow{2}{*}{ Variable } & \multicolumn{5}{|c|}{ All Firms } & \multicolumn{4}{c}{ Survived Firms } \\
\cline { 2 - 11 } & Mean & Std Dev & $5 \%$ & Median & $95 \%$ & Mean & Std Dev & $5 \%$ & Median & $95 \%$ \\
\hline Book Leverage & 0.252 & 0.210 & 0.000 & 0.227 & 0.647 & 0.248 & 0.194 & 0.000 & 0.232 & 0.596 \\
Market Leverage & 0.279 & 0.258 & 0.000 & 0.216 & 0.783 & 0.286 & 0.249 & 0.000 & 0.233 & 0.760 \\
Initial Leverage & 0.277 & 0.248 & 0.000 & 0.229 & 0.766 & 0.264 & 0.228 & 0.000 & 0.225 & 0.699 \\
$\ln$ (Sales) & 4.365 & 2.430 & 0.334 & 4.360 & 8.317 & 4.825 & 2.210 & 1.374 & 4.758 & 8.534 \\
Book/Market & 1.648 & 2.739 & 0.408 & 0.998 & 4.618 & 1.433 & 1.964 & 0.422 & 0.951 & 3.828 \\
ROA & 0.061 & 0.306 & -0.347 & 0.113 & 0.288 & 0.110 & 0.194 & -0.129 & 0.126 & 0.292 \\
Tangible Assets & 0.320 & 0.249 & 0.016 & 0.260 & 0.828 & 0.341 & 0.245 & 0.026 & 0.286 & 0.835 \\
$\ln$ (Total Assets) & 4.540 & 2.248 & 1.154 & 4.350 & 8.524 & 4.866 & 2.154 & 1.668 & 4.661 & 8.688 \\
$\ln$ (CF Volatility) & 3.069 & 2.133 & -0.087 & 2.847 & 6.902 & 3.436 & 2.085 & 0.358 & 3.275 & 7.112 \\
Dividend Dummy & 0.501 & 0.500 & 0.000 & 1.000 & 1.000 & 0.590 & 0.492 & 0.000 & 1.000 & 1.000 \\
\# of Observations & 204904 & & & & & 142874 & & & & \\
\# of Firms & 18715 & & & & & 7457 & & & & \\
\hline \hline
\end{tabular}




\section{Table 2: Pooled Regression for All Firms}

This table reports the pooled regression results when using either the book leverage or the market leverage as the response variables. The data set contains 18715 firms with 204904 firm-year observations from 1965 to 2006. Standard Deviation is in parentheses; $\left({ }^{*}\right)$ denotes estimates that are significant at $95 \%$ confidence level. These standard errors are Arellano's HAC in Firm Cluster model. Variable definition can be found in the Appendix.

\begin{tabular}{|c|c|c|c|c|c|c|c|c|}
\hline \multirow[b]{2}{*}{ Variable } & \multicolumn{4}{|c|}{ "Book leverage } & \multicolumn{4}{|c|}{ "Market leverage } \\
\hline & $(1)$ & $(2)$ & $(3)$ & $(4)$ & $(1)$ & $(2)$ & $(3)$ & $(4)$ \\
\hline \multirow[t]{2}{*}{ Initial Leverage } & $0.3298^{*}$ & & & $0.2848^{*}$ & $0.3279^{*}$ & & & $0.2710^{*}$ \\
\hline & $(.0063)$ & & & $(.0058)$ & $(.0077)$ & & & $(.0062)$ \\
\hline \multirow[t]{2}{*}{$\ln$ (Sales) } & & -0.0027 & $0.0034^{*}$ & -0.0007 & & $0.0062^{*}$ & $0.0029^{*}$ & $0.0084^{*}$ \\
\hline & & $(.0014)$ & $(.0015)$ & $(.0012)$ & & $(.0015)$ & $(.0014)$ & $(.0014)$ \\
\hline \multirow[t]{2}{*}{ Book/Market } & & $-0.0037^{*}$ & $-0.0021^{*}$ & $-0.0031^{*}$ & & $-0.0148^{*}$ & $-0.0108^{*}$ & $-0.0143^{*}$ \\
\hline & & $(.0006)$ & $(.0003)$ & $(.0006)$ & & $(.0013)$ & $(.0006)$ & $(.0013)$ \\
\hline \multirow[t]{2}{*}{$\mathrm{ROA}$} & & $-0.0825^{*}$ & $-0.0897^{*}$ & $-0.0727^{*}$ & & $-0.1013^{*}$ & $-0.1097^{*}$ & $-0.0923^{*}$ \\
\hline & & $(.0054)$ & $(.0041)$ & $(.0054)$ & & $(.0109)$ & $(.0048)$ & $(.0110)$ \\
\hline \multirow[t]{2}{*}{ Tangible Assets } & & $0.1716^{*}$ & $0.2351^{*}$ & $0.1443^{*}$ & & $0.1442^{*}$ & $0.2056^{*}$ & $0.1136^{*}$ \\
\hline & & $(.0068)$ & $(.0087)$ & $(.0058)$ & & $(.0073)$ & $(.0092)$ & $(.0065)$ \\
\hline \multirow[t]{2}{*}{$\ln$ (Total Assets) } & & $0.0362^{*}$ & $0.0196^{*}$ & $0.0333^{*}$ & & $0.0548^{*}$ & $0.0356^{*}$ & $0.0521^{*}$ \\
\hline & & $(.0019)$ & $(.0018)$ & $(.0017)$ & & $(.0021)$ & $(.0018)$ & $(.0019)$ \\
\hline \multirow[t]{2}{*}{$\ln (\mathrm{CF}$ Volatility $)$} & & $-0.0242^{*}$ & $0.0011^{*}$ & $-0.0230^{*}$ & & $-0.0498^{*}$ & $0.0016^{*}$ & $-0.0490^{*}$ \\
\hline & & $(.0013)$ & $(.0001)$ & $(.0011)$ & & $(.0015)$ & $(.0001)$ & $(.0015)$ \\
\hline \multirow[t]{2}{*}{ Dividend Dummy } & & $-0.0352^{*}$ & $-0.0082^{*}$ & $-0.0250^{*}$ & & $-0.0381^{*}$ & $-0.0115^{*}$ & $-0.0277^{*}$ \\
\hline & & $(.0025)$ & $(.0008)$ & $(.0023)$ & & $(.0029)$ & $(.0009)$ & $(.0027)$ \\
\hline \multirow[t]{2}{*}{ Industry Median } & & $0.4590^{*}$ & $0.3912^{*}$ & $0.3076^{*}$ & & $0.5284^{*}$ & $0.5966^{*}$ & $0.4360^{*}$ \\
\hline & & $(.0164)$ & $(.0181)$ & $(.0150)$ & & $(.0138)$ & $(.0105)$ & $(.0130)$ \\
\hline Adjusted $R^{2}$ & 0.1510 & 0.1647 & 0.6663 & 0.2701 & 0.099 & 0.2912 & 0.6985 & 0.3548 \\
\hline Year Fixed Effect & No & Yes & No & Yes & No & Yes & No & Yes \\
\hline Firm Fixed Effect & No & No & Yes & No & No & No & Yes & No \\
\hline
\end{tabular}




\section{Table 3: Pooled Regression for Survived Firms}

This table reports the pooled regression results when using either the book leverage or the market leverage as the response variables. The data set contains 7457 firms with 142874 firm-year observations from 1965 to 2006. Standard Deviation is in parentheses; $\left({ }^{*}\right)$ denotes estimates that are significant at $95 \%$ confidence level. These standard errors are Arellano's HAC in Firm Cluster model. Variable definition can be found in the Appendix.

\begin{tabular}{|c|c|c|c|c|c|c|c|c|}
\hline \multirow[b]{2}{*}{ Variable } & \multicolumn{4}{|c|}{ "Book leverage } & \multicolumn{4}{|c|}{ "Market leverage } \\
\hline & $(1)$ & $(2)$ & $(3)$ & $(4)$ & $(1)$ & $(2)$ & $(3)$ & $(4)$ \\
\hline \multirow[t]{2}{*}{ Initial Leverage } & $0.3422^{*}$ & & & $0.2798^{*}$ & $0.3705^{*}$ & & & $0.2847^{*}$ \\
\hline & $(.0088)$ & & & $(.0081)$ & $(.0112)$ & & & $(.0089)$ \\
\hline \multirow[t]{2}{*}{$\ln$ (Sales) } & & $-0.0099^{*}$ & $-0.0086^{*}$ & $-0.0059^{*}$ & & 0.0020 & -0.0024 & $0.0063^{*}$ \\
\hline & & $(.0025)$ & $(.0022)$ & $(.0021)$ & & $(.0028)$ & $(.0023)$ & $(.0024)$ \\
\hline \multirow[t]{2}{*}{ Book/Market } & & $-0.0060^{*}$ & $-0.0026^{*}$ & $-0.0049^{*}$ & & $-0.0200^{*}$ & $-0.0158^{*}$ & $-0.0190^{*}$ \\
\hline & & $(.0016)$ & $(.0006)$ & $(.0015)$ & & $(.0037)$ & $(.0013)$ & $(.0037)$ \\
\hline \multirow[t]{2}{*}{$\mathrm{ROA}$} & & $-0.1029^{*}$ & $-0.1310^{*}$ & $-0.0950^{*}$ & & $-0.1536^{*}$ & $-0.1996^{*}$ & $-0.1459^{*}$ \\
\hline & & $(.0151)$ & $(.0082)$ & $(.0145)$ & & $(.0329)$ & $(.0127)$ & $(.0326)$ \\
\hline \multirow[t]{2}{*}{ Tangible Assets } & & $0.1557^{*}$ & $0.2307^{*}$ & $0.1268^{*}$ & & $0.1364^{*}$ & $0.2117^{*}$ & $0.1024^{*}$ \\
\hline & & $(.0092)$ & $(.0100)$ & $(.0079)$ & & $(.0103)$ & $(.0112)$ & $(.0092)$ \\
\hline \multirow[t]{2}{*}{$\ln$ (Total Assets) } & & $0.0417^{*}$ & $0.0274^{*}$ & $0.0372^{*}$ & & $0.0561^{*}$ & $0.0349^{*}$ & $0.0516^{*}$ \\
\hline & & $(.0030)$ & $(.0024)$ & $(.0025)$ & & $(.0035)$ & $(.0026)$ & $(.0032)$ \\
\hline \multirow[t]{2}{*}{$\ln (\mathrm{CF}$ Volatility $)$} & & $-0.0211^{*}$ & $0.0013^{*}$ & $-0.0206^{*}$ & & $-0.0465^{*}$ & $0.0019^{*}$ & $-0.0464^{*}$ \\
\hline & & $(.0017)$ & $(.0001)$ & $(.0015)$ & & $(.0023)$ & $(.0002)$ & $(.0021)$ \\
\hline \multirow[t]{2}{*}{ Dividend Dummy } & & $-0.0420^{*}$ & $-0.0084^{*}$ & $-0.0286^{*}$ & & $-0.0490^{*}$ & $-0.0129^{*}$ & $-0.0348^{*}$ \\
\hline & & $(.0031)$ & $(.0009)$ & $(.0028)$ & & $(.0036)$ & $(.0011)$ & $(.0034)$ \\
\hline \multirow[t]{2}{*}{ Industry Median } & & $0.4344^{*}$ & $0.3973^{*}$ & $0.2744^{*}$ & & $0.5061^{*}$ & $0.5922^{*}$ & $0.4022^{*}$ \\
\hline & & $(.0208)$ & $(.0191)$ & $(.0190)$ & & $(.0192)$ & $(.0113)$ & $(.0183)$ \\
\hline Adjusted $R^{2}$ & 0.1620 & 0.1978 & 0.6575 & 0.2961 & 0.1140 & 0.3214 & 0.6945 & 0.3835 \\
\hline Year Fixed Effect & No & Yes & No & Yes & No & Yes & No & Yes \\
\hline Firm Fixed Effect & No & No & Yes & No & No & No & Yes & No \\
\hline
\end{tabular}




\section{Table 4: Explanining the Dynamics of Leverage for Survived Firms}

This table reports the dynamic panel regression results of Model I when using either the book leverage or the market leverage as the response variables. The data set contains 7457 firms with 135411 firmyear observations from 1965 to 2006. Standard Deviation is in parentheses; $\left(^{*}\right)$ denotes estimates that are significant at 95\% confidence level. These standard errors are Arellano's HAC in Firm Cluster model. Variable definition can be found in the Appendix.

\begin{tabular}{|c|c|c|c|c|c|c|c|c|}
\hline \multirow[b]{2}{*}{ Variable } & \multicolumn{4}{|c|}{ 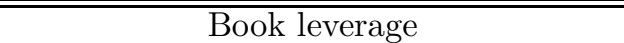 } & \multicolumn{4}{|c|}{ Market leverage } \\
\hline & (1) & $(2)$ & $(3)$ & (4) & (1) & $(2)$ & $(3)$ & $(4)$ \\
\hline Lagged Leverage & $\begin{array}{l}0.6846^{*} \\
(.0019) \\
\end{array}$ & & $\begin{array}{c}0.6760^{*} \\
(.0045)\end{array}$ & $\begin{array}{c}0.6466^{*} \\
(.0048)\end{array}$ & $\begin{array}{l}0.7013^{*} \\
(.0035)\end{array}$ & & $\begin{array}{c}0.6938^{*} \\
(.0035)\end{array}$ & $\begin{array}{c}0.6218^{*} \\
(.0042)\end{array}$ \\
\hline \multicolumn{9}{|c|}{ Variables are in mean } \\
\hline $\ln$ (Sales) & & $\begin{array}{c}-0.0154^{*} \\
(.0034)\end{array}$ & $\begin{array}{c}-0.0453^{*} \\
(.0034)\end{array}$ & $\begin{array}{r}-0.0156^{*} \\
(.0034)\end{array}$ & & $\begin{array}{c}-0.0010 \\
(.0038)\end{array}$ & $\begin{array}{l}0.0009 \\
(.0038)\end{array}$ & $\begin{array}{c}-0.0014 \\
(.0038)\end{array}$ \\
\hline Book/Market & & $\begin{array}{r}-0.0136^{*} \\
(.0037)\end{array}$ & $\begin{array}{c}-0.0131^{*} \\
(.0037)\end{array}$ & $\begin{array}{r}-0.0130^{*} \\
(.0038)\end{array}$ & & $\begin{array}{r}-0.0285^{*} \\
(.0076)\end{array}$ & $\begin{array}{c}-0.0279^{*} \\
(.0076)\end{array}$ & $\begin{array}{r}-0.0279^{*} \\
(.0078)\end{array}$ \\
\hline $\mathrm{ROA}$ & & $\begin{array}{c}-0.0400 \\
(.0276)\end{array}$ & $\begin{array}{c}-0.0503 \\
(.0279)\end{array}$ & $\begin{array}{c}-0.0496 \\
(.0281)\end{array}$ & & $\begin{array}{r}-0.0567 \\
(.0549)\end{array}$ & $\begin{array}{c}-0.0670 \\
(.0550)\end{array}$ & $\begin{array}{l}-0.0652 \\
(.0555)\end{array}$ \\
\hline Tangible Assets & & $\begin{array}{c}0.1227^{*} \\
(.0120)\end{array}$ & $\begin{array}{c}0.1229^{*} \\
(.0120)\end{array}$ & $\begin{array}{c}0.1226^{*} \\
(.0120)\end{array}$ & & $\begin{array}{c}0.1058^{*} \\
(.0131)\end{array}$ & $\begin{array}{c}0.1059^{*} \\
(.0131)\end{array}$ & $\begin{array}{r}0.1055^{*} \\
(.0131)\end{array}$ \\
\hline $\ln$ (Total Assets) & & $\begin{array}{c}0.0413^{*} \\
(.0049)\end{array}$ & $\begin{array}{c}0.0405^{*} \\
(.0049)\end{array}$ & $\begin{array}{c}0.0409^{*} \\
(.0049)\end{array}$ & & $\begin{array}{c}0.0657^{*} \\
(.0068)\end{array}$ & $\begin{array}{c}0.0650^{*} \\
(.0068)\end{array}$ & $\begin{array}{c}0.0657^{*} \\
(.0069)\end{array}$ \\
\hline $\ln$ (CF Volatility) & & $\begin{array}{r}-0.0182^{*} \\
(.0036)\end{array}$ & $\begin{array}{r}-0.0183^{*} \\
(.0036)\end{array}$ & $\begin{array}{r}-0.0185^{*} \\
(.0036)\end{array}$ & & $\begin{array}{r}-0.0565^{*} \\
(.0058)\end{array}$ & $\begin{array}{c}-0.0571^{*} \\
(.0058)\end{array}$ & $\begin{array}{r}-0.0572^{*} \\
(.0059)\end{array}$ \\
\hline Dividend Dummy & & $\begin{array}{r}-0.0346^{*} \\
(.0031)\end{array}$ & $\begin{array}{c}-0.0265^{*} \\
(.0029)\end{array}$ & $\begin{array}{r}-0.0268^{*} \\
(.0030)\end{array}$ & & $\begin{array}{r}-0.0379^{*} \\
(.0038)\end{array}$ & $\begin{array}{r}-0.0255^{*} \\
(.0035)\end{array}$ & $\begin{array}{r}-0.0276^{*} \\
(.0035)\end{array}$ \\
\hline Industry Median & & $\begin{array}{c}0.5375^{*} \\
(.0290) \\
\end{array}$ & $\begin{array}{c}0.5265^{*} \\
(.0291) \\
\end{array}$ & $\begin{array}{r}0.5281^{*} \\
(.0291) \\
\end{array}$ & & $\begin{array}{r}0.6095^{*} \\
(.0264) \\
\end{array}$ & $\begin{array}{c}0.5979^{*} \\
(.0264) \\
\end{array}$ & $\begin{array}{r}0.5968^{*} \\
(.0265) \\
\end{array}$ \\
\hline \multicolumn{9}{|c|}{ Demeaned Variables } \\
\hline $\ln$ (Sales) & & & & $\begin{array}{r}-0.0114^{*} \\
(.0016)\end{array}$ & & & & $\begin{array}{r}-0.0178^{*} \\
(.0017)\end{array}$ \\
\hline Book/Market & & & & $\begin{array}{c}-0.0004 \\
(.0005)\end{array}$ & & & & $\begin{array}{r}-0.0085^{*} \\
(.0009)\end{array}$ \\
\hline $\mathrm{ROA}$ & & & & $\begin{array}{c}-0.1051^{*} \\
(.0068)\end{array}$ & & & & $\begin{array}{c}-0.1312^{*} \\
(.0089)\end{array}$ \\
\hline Tangible Assets & & & & $\begin{array}{c}0.1247^{*} \\
(.0058)\end{array}$ & & & & $\begin{array}{c}0.1300^{*} \\
(.0065)\end{array}$ \\
\hline $\ln$ (Total Assets) & & & & $\begin{array}{c}0.0226^{*} \\
(.0016)\end{array}$ & & & & $\begin{array}{c}0.0365^{*} \\
(.0017)\end{array}$ \\
\hline Industry Median & & & & $\begin{array}{r}0.1959^{*} \\
(.0101) \\
\end{array}$ & & & & $\begin{array}{r}0.3232^{*} \\
(.0064)\end{array}$ \\
\hline Adjusted $R^{2}$ & 0.1690 & 0.1620 & 0.3260 & 0.3390 & 0.1810 & 0.2450 & 0.4220 & 0.4460 \\
\hline
\end{tabular}




\section{Table 5: Explanining the Dynamics of Leverage for Survived Firms with}

\section{Time Trend}

This table reports the dynamic panel regression results of Model I when using either the book leverage or the market leverage as the response variables. The data set contains 7457 firms with 135411 firmyear observations from 1965 to 2006. Standard Deviation is in parentheses; $\left(^{*}\right)$ denotes estimates that are significant at 95\% confidence level. These standard errors are Arellano's HAC in Firm Cluster model. Variable definition can be found in the Appendix.

\begin{tabular}{|c|c|c|c|c|c|c|c|c|}
\hline \multirow[b]{2}{*}{ Variable } & \multicolumn{4}{|c|}{$\overline{\text { Book leverage }}$} & \multicolumn{4}{|c|}{ Market leverage } \\
\hline & (1) & $(2)$ & (3) & (4) & (1) & $(2)$ & $(3)$ & (4) \\
\hline Lagged Leverage & $\begin{array}{c}0.6859^{*} \\
(.0047)\end{array}$ & & $\begin{array}{c}0.6756^{*} \\
(.0045)\end{array}$ & $\begin{array}{c}0.6458^{*} \\
(.0028)\end{array}$ & $\begin{array}{c}0.7077^{*} \\
(.0038)\end{array}$ & & $\begin{array}{c}0.6902^{*} \\
(.0036)\end{array}$ & $\begin{array}{l}0.6272^{*} \\
(.0042)\end{array}$ \\
\hline Time trend(Year) & $\begin{array}{c}-0.0019^{*} \\
(.0001)\end{array}$ & $\begin{array}{c}-0.0006^{*} \\
(.0001)\end{array}$ & $\begin{array}{c}-0.0008^{*} \\
(.0001)\end{array}$ & $\begin{array}{c}-0.0016^{*} \\
(.0002)\end{array}$ & $\begin{array}{c}-0.0039^{*} \\
(.0002)\end{array}$ & $\begin{array}{c}-0.0004^{*} \\
(.0002)\end{array}$ & $\begin{array}{r}-0.0012^{*} \\
(.0001)\end{array}$ & $\begin{array}{r}-0.0026^{*} \\
(.0002)\end{array}$ \\
\hline RecessionDummy & $\begin{array}{c}0.0043^{*} \\
(.0007)\end{array}$ & $\begin{array}{c}0.0130^{*} \\
(.0009)\end{array}$ & $\begin{array}{c}0.0042^{*} \\
(.0007)\end{array}$ & $\begin{array}{c}0.0012^{*} \\
(.0007)\end{array}$ & $\begin{array}{c}0.0308^{*} \\
(.0010)\end{array}$ & $\begin{array}{c}0.0549^{*} \\
(.0012)\end{array}$ & $\begin{array}{c}0.0289^{*} \\
(.0009)\end{array}$ & $\begin{array}{l}0.0121^{*} \\
(.0009)\end{array}$ \\
\hline \multicolumn{9}{|c|}{ Variables are in mean } \\
\hline $\ln$ (Sales) & & $\begin{array}{c}-0.0161^{*} \\
(.0034)\end{array}$ & $\begin{array}{c}-0.0161^{*} \\
(.0034)\end{array}$ & $\begin{array}{c}-0.0170^{*} \\
(.0034)\end{array}$ & & $\begin{array}{c}-0.0020 \\
(.0038)\end{array}$ & $\begin{array}{r}-0.0023 \\
(.0038)\end{array}$ & $\begin{array}{c}-0.0038 \\
(.0038)\end{array}$ \\
\hline Book/Market & & $\begin{array}{c}-0.0127^{*} \\
(.0037)\end{array}$ & $\begin{array}{r}-0.0122^{*} \\
(.0037)\end{array}$ & $\begin{array}{c}-0.0113 \\
(.0037)\end{array}$ & & $\begin{array}{r}-0.0275^{*} \\
(.0076)\end{array}$ & $\begin{array}{r}-0.0264^{*} \\
(.0076)\end{array}$ & $\begin{array}{r}-0.0253^{*} \\
(.0077)\end{array}$ \\
\hline $\mathrm{ROA}$ & & $\begin{array}{c}-0.0453 \\
(.0273)\end{array}$ & $\begin{array}{c}-0.0560^{*} \\
(.0276)\end{array}$ & $\begin{array}{c}-0.0603^{*} \\
(.0276)\end{array}$ & & $\begin{array}{c}-0.0633 \\
(.0547)\end{array}$ & $\begin{array}{r}-0.0771 \\
(.0547)\end{array}$ & $\begin{array}{c}-0.0822 \\
(.0553)\end{array}$ \\
\hline Tangible Assets & & $\begin{array}{c}0.1237^{*} \\
(.0120)\end{array}$ & $\begin{array}{c}0.1238^{*} \\
(.0119)\end{array}$ & $\begin{array}{l}0.1244^{*} \\
(.0119)\end{array}$ & & $\begin{array}{c}0.1076^{*} \\
(.0131)\end{array}$ & $\begin{array}{c}0.1073^{*} \\
(.0131)\end{array}$ & $\begin{array}{l}0.1077^{*} \\
(.0131)\end{array}$ \\
\hline $\ln$ (Total Assets) & & $\begin{array}{l}0.0433^{*} \\
(.0049)\end{array}$ & $\begin{array}{c}0.0426^{*} \\
(.0049)\end{array}$ & $\begin{array}{l}0.0451^{*} \\
(.0049)\end{array}$ & & $\begin{array}{c}0.0689^{*} \\
(.0069)\end{array}$ & $\begin{array}{c}0.0694^{*} \\
(.0069)\end{array}$ & $\begin{array}{c}0.0734^{*} \\
(.0069)\end{array}$ \\
\hline $\ln (\mathrm{CF}$ Volatility) & & $\begin{array}{c}-0.0187^{*} \\
(.0036)\end{array}$ & $\begin{array}{c}-0.0188^{*} \\
(.0036)\end{array}$ & $\begin{array}{c}-0.0195^{*} \\
(.0036)\end{array}$ & & $\begin{array}{c}-0.0574^{*} \\
(.0058)\end{array}$ & $\begin{array}{r}-0.0584^{*} \\
(.0058)\end{array}$ & $\begin{array}{r}-0.0597^{*} \\
(.0059)\end{array}$ \\
\hline Dividend Dummy & & $\begin{array}{c}-0.0388^{*} \\
(.0032)\end{array}$ & $\begin{array}{c}-0.0310^{*} \\
(.0030)\end{array}$ & $\begin{array}{c}-0.0364^{*} \\
(.0031)\end{array}$ & & $\begin{array}{c}-0.0431^{*} \\
(.0038)\end{array}$ & $\begin{array}{r}-0.0333^{*} \\
(.0035)\end{array}$ & $\begin{array}{r}-0.0426^{*} \\
(.0036)\end{array}$ \\
\hline Industry Median & & $\begin{array}{c}0.5083^{*} \\
(.0289)\end{array}$ & $\begin{array}{c}0.4970^{*} \\
(.0288)\end{array}$ & $\begin{array}{l}0.4713^{*} \\
(.0289)\end{array}$ & & $\begin{array}{c}0.5770^{*} \\
(.0264)\end{array}$ & $\begin{array}{c}0.5546^{*} \\
(.0262)\end{array}$ & $\begin{array}{r}0.5245^{*} \\
(.0267)\end{array}$ \\
\hline \multicolumn{9}{|l|}{ Demeaned variables } \\
\hline $\ln$ (Sales) & & & & $\begin{array}{c}-0.0085^{*} \\
(.0016)\end{array}$ & & & & $\begin{array}{r}-0.0125^{*} \\
(.0017)\end{array}$ \\
\hline Book/Market & & & & $\begin{array}{c}-0.0002 \\
(.0005)\end{array}$ & & & & $\begin{array}{r}-0.0081^{*} \\
(.0009)\end{array}$ \\
\hline $\mathrm{ROA}$ & & & & $\begin{array}{c}-0.1156^{*} \\
(.0072)\end{array}$ & & & & $\begin{array}{r}-0.1490^{*} \\
(.0098)\end{array}$ \\
\hline Tangible Assets & & & & $\begin{array}{c}0.1152^{*} \\
(.0059)\end{array}$ & & & & $\begin{array}{l}0.1105^{*} \\
(.0067)\end{array}$ \\
\hline $\ln$ (Total Assets) & & & & $\begin{array}{c}0.0295^{*} \\
(.0017)\end{array}$ & & & & $\begin{array}{c}0.0478^{*} \\
(.0019)\end{array}$ \\
\hline Industry Median & & & & $\begin{array}{l}0.1383^{*} \\
(.0115)\end{array}$ & & & & $\begin{array}{l}0.2611^{*} \\
(.0071)\end{array}$ \\
\hline Adjusted $R^{2}$ & 0.1820 & 0.1640 & 0.3230 & 0.3430 & 0.2200 & 0.2550 & 0.4280 & 0.4540 \\
\hline
\end{tabular}


Table 6: Explanining the Dynamics of Leverage for Survived Firms with Time-varying Rho

This table reports the dynamic panel regression results of Model I when using either the book leverage or the market leverage as the response variables. The data set contains 7457 firms with 135411 firmyear observations from 1965 to 2006. Standard Deviation is in parentheses; $\left(^{*}\right)$ denotes estimates that are significant at $95 \%$ confidence level. These standard errors are Arellano's HAC in Firm Cluster model. Variable definition can be found in the Appendix.

\begin{tabular}{|c|c|c|c|c|c|c|}
\hline \multirow[b]{2}{*}{ Variable } & \multicolumn{3}{|c|}{$\overline{\text { Book leverage }}$} & \multicolumn{3}{|c|}{ Market leverage } \\
\hline & (1) & $(3)$ & (4) & (1) & $(3)$ & (4) \\
\hline Lagged Leverage & $\begin{array}{l}0.6685^{*} \\
(.0056)\end{array}$ & $\begin{array}{l}0.6610^{*} \\
(.0054)\end{array}$ & $\begin{array}{l}0.6322^{*} \\
(.0056)\end{array}$ & $\begin{array}{l}0.6864^{*} \\
(.0050)\end{array}$ & $\begin{array}{l}0.6801^{*} \\
(.0045)\end{array}$ & $\begin{array}{l}0.6182^{*} \\
(.0049)\end{array}$ \\
\hline$l_{t-1} \times$ & & & & & & \\
\hline RecessionDummy & $\begin{array}{c}0.0739^{*} \\
(.0123)\end{array}$ & $\begin{array}{l}0.0622^{*} \\
(.0118)\end{array}$ & $\begin{array}{l}0.0579^{*} \\
(.0116)\end{array}$ & $\begin{array}{c}0.0723^{*} \\
(.0100)\end{array}$ & $\begin{array}{c}0.0341^{*} \\
(.0092)\end{array}$ & $\begin{array}{c}0.0310^{*} \\
(.0090)\end{array}$ \\
\hline Time trend (Year) & $\begin{array}{c}-0.0019^{*} \\
(.0001)\end{array}$ & $\begin{array}{c}-0.0008^{*} \\
(.0001)\end{array}$ & $\begin{array}{c}-0.0016^{*} \\
(.0002)\end{array}$ & $\begin{array}{c}-0.0039^{*} \\
(.0002)\end{array}$ & $\begin{array}{c}-0.0012^{*} \\
(.0001)\end{array}$ & $\begin{array}{c}-0.0026^{*} \\
(.0002)\end{array}$ \\
\hline Recession Dummy & $\begin{array}{c}0.0039^{*} \\
(.0007)\end{array}$ & $\begin{array}{l}0.0039^{*} \\
(.0007)\end{array}$ & $\begin{array}{c}0.0009^{*} \\
(.0007)\end{array}$ & $\begin{array}{c}0.0299^{*} \\
(.0010)\end{array}$ & $\begin{array}{c}0.0285^{*} \\
(.0009)\end{array}$ & $\begin{array}{l}0.0118^{*} \\
(.0010)\end{array}$ \\
\hline \multicolumn{7}{|c|}{ Variables are in mean } \\
\hline $\ln$ (Sales) & & $\begin{array}{c}-0.0161^{*} \\
(.0034)\end{array}$ & $\begin{array}{c}-0.0171^{*} \\
(.0034)\end{array}$ & & $\begin{array}{c}-0.0023 \\
(.0038)\end{array}$ & $\begin{array}{c}-0.0038 \\
(.0038)\end{array}$ \\
\hline Book/Market & & $\begin{array}{c}-0.0122^{*} \\
(.0037)\end{array}$ & $\begin{array}{l}-0.0113 \\
(.0037)\end{array}$ & & $\begin{array}{c}-0.0263^{*} \\
(.0076)\end{array}$ & $\begin{array}{r}-0.0253^{*} \\
(.0077)\end{array}$ \\
\hline ROA & & $\begin{array}{c}-0.0560^{*} \\
(.0276)\end{array}$ & $\begin{array}{c}-0.0604^{*} \\
(.0276)\end{array}$ & & $\begin{array}{r}-0.0770 \\
(.0547)\end{array}$ & $\begin{array}{r}-0.0821 \\
(.0552)\end{array}$ \\
\hline Tangible Assets & & $\begin{array}{l}0.1239^{*} \\
(.0119)\end{array}$ & $\begin{array}{c}0.1245^{*} \\
(.0119)\end{array}$ & & $\begin{array}{c}0.1074^{*} \\
(.0131)\end{array}$ & $\begin{array}{c}0.1078^{*} \\
(.0131)\end{array}$ \\
\hline $\ln$ (Total Assets) & & $\begin{array}{l}0.0426^{*} \\
(.0049)\end{array}$ & $\begin{array}{l}0.0452^{*} \\
(.0049)\end{array}$ & & $\begin{array}{c}0.0694^{*} \\
(.0069)\end{array}$ & $\begin{array}{l}0.0735^{*} \\
(.0069)\end{array}$ \\
\hline $\ln$ (CF Volatility) & & $\begin{array}{c}-0.0187^{*} \\
(.0036)\end{array}$ & $\begin{array}{r}-0.0195^{*} \\
(.0036)\end{array}$ & & $\begin{array}{r}-0.0584^{*} \\
(.0058)\end{array}$ & $\begin{array}{c}-0.0597^{*} \\
(.0059)\end{array}$ \\
\hline Dividend Dummy & & $\begin{array}{c}-0.0309^{*} \\
(.0030)\end{array}$ & $\begin{array}{c}-0.0364^{*} \\
(.0031)\end{array}$ & & $\begin{array}{c}-0.0333^{*} \\
(.0035)\end{array}$ & $\begin{array}{c}-0.0426^{*} \\
(.0036)\end{array}$ \\
\hline Industry Median & & $\begin{array}{l}0.4964^{*} \\
(.0288)\end{array}$ & $\begin{array}{l}0.4707^{*} \\
(.0289)\end{array}$ & & $\begin{array}{c}0.5541^{*} \\
(.0262)\end{array}$ & $\begin{array}{c}0.5240^{*} \\
(.0267)\end{array}$ \\
\hline \multicolumn{7}{|l|}{ Demeaned variables } \\
\hline$\overline{\ln \text { (Sales) }}$ & & & $\begin{array}{c}-0.0084^{*} \\
(.0002)\end{array}$ & & & $\begin{array}{c}-0.0124^{*} \\
(.0017)\end{array}$ \\
\hline Book/Market & & & $\begin{array}{l}-0.0002 \\
(.0005)\end{array}$ & & & $\begin{array}{r}-0.0081^{*} \\
(.0009)\end{array}$ \\
\hline ROA & & & $\begin{array}{c}-0.1160^{*} \\
(.0072)\end{array}$ & & & $\begin{array}{c}-0.1490^{*} \\
(.0098)\end{array}$ \\
\hline Tangible Assets & & & $\begin{array}{l}0.1149^{*} \\
(.0059)\end{array}$ & & & $\begin{array}{c}0.1106^{*} \\
(.0067)\end{array}$ \\
\hline $\ln$ (Total Assets) & & & $\begin{array}{l}0.0294^{*} \\
(.0017)\end{array}$ & & & $\begin{array}{c}0.0478^{*} \\
(.0019)\end{array}$ \\
\hline Industry Median & & & $\begin{array}{l}0.1376^{*} \\
(.0115)\end{array}$ & & & $\begin{array}{l}0.2600^{*} \\
(.0071)\end{array}$ \\
\hline Adjusted $R^{2}$ & 0.1820 & 0.3280 & 0.3440 & 0.2200 & 0.4280 & 0.4540 \\
\hline
\end{tabular}




\section{Table 7: Descriptive Statistics For Survived Firms}

This table reports the descriptive statistics for the leverage variables and the leverage determinants for the following two subsamples of the set of survived firms. The first subsample contains firms for which Model I(a) produces the estimate of $\rho_{i}$ that lies within the unit interval. The second subsample contains all the remaining survived firms. The "Survived firms" are the firms that have at least 10 years of consecutive records. Variable definition can be found in the Appendix.

\begin{tabular}{l|ccc|ccc}
\hline \hline \multirow{2}{*}{ Variable } & \multicolumn{3}{|c|}{ Firms with $\rho_{i} \in(0,1)$} & \multicolumn{3}{c}{ Firms with $\rho_{i} \notin(0,1)$} \\
\cline { 2 - 7 } Book Leverage & 0.269 & Std Dev & Median & Mean & Std Dev & Median \\
\hline Market Leverage & 0.305 & 0.240 & 0.254 & 0.193 & 0.212 & 0.119 \\
Initial Leverage & 0.278 & 0.224 & 0.245 & 0.231 & 0.266 & 0.115 \\
$\ln$ (Sales) & 5.070 & 2.163 & 5.013 & 4.133 & 0.233 & 0.164 \\
Book/Market & 1.332 & 1.534 & 0.940 & 1.720 & 2.829 & 4.070 \\
ROA & 0.115 & 0.153 & 0.128 & 0.098 & 0.278 & 0.118 \\
Tangible Assets & 0.359 & 0.242 & 0.304 & 0.290 & 0.247 & 0.226 \\
$\ln$ (Total Assets) & 5.060 & 2.153 & 4.882 & 4.319 & 2.062 & 4.076 \\
$\ln$ (CF Volatility) & 3.651 & 2.093 & 3.555 & 2.829 & 1.936 & 2.552 \\
Dividend Dummy & 0.606 & 0.489 & 1.000 & 0.543 & 0.498 & 1.000 \\
\# of Observations & 105514 & & & 37364 & & \\
\# of Firms & 4955 & & & 2502 & & \\
\hline \hline
\end{tabular}




\section{Table 8: Correlation Among Parameter Estimates}

This table reports the correlation coefficients between quarter and annual estimates of the longterm mean $\bar{l}$, persistence $\rho$, and residual standard deviation $\sigma$ using both book leverage and market leverage. The data set contains 4955 firms and 4766 firms when using book leverage and market leverage, respectively, from 1965 to 2006.

\begin{tabular}{c|cc|cc|cc}
\hline \hline Parameter & $l_{\text {quarter }}$ & $l_{\text {annual }}$ & $\bar{\rho}_{\text {quarter }}$ & $\bar{\rho}_{\text {annual }}$ & $\bar{\sigma}_{\text {quarter }}$ & $\bar{\sigma}_{\text {annual }}$ \\
\hline & \multicolumn{7}{|c}{ Book leverage } \\
\hline $\bar{l}_{\text {quarter }}$ & 1.0000 & & \multicolumn{5}{c}{} & & \\
$\bar{l}_{\text {annual }}$ & 0.9571 & 1.0000 & & & & \\
\hline $\bar{\rho}_{\text {quarter }}$ & 0.0279 & 0.0417 & 1.0000 & & & \\
$\bar{\rho}_{\text {annual }}$ & 0.1075 & 0.1151 & 0.5503 & 1.0000 & & \\
\hline $\bar{\sigma}_{\text {quarter }}$ & 0.1588 & 0.1491 & -0.2063 & -0.1716 & 1.0000 & \\
$\bar{\sigma}_{\text {annual }}$ & 0.1198 & 0.1438 & 0.0779 & -0.1390 & 0.7656 & 1.0000 \\
\hline & \multicolumn{7}{|c|}{ Market leverage } \\
\hline$l_{\text {quarter }}$ & 1.0000 & \multicolumn{7}{|c}{} & & \\
$\bar{l}_{\text {annual }}$ & 0.9584 & 1.0000 & 1.0000 & & & \\
\hline $\bar{\rho}_{\text {quarter }}$ & 0.0495 & 0.0796 & 1.5328 & 1.0000 & & \\
$\bar{\rho}_{\text {annual }}$ & 0.2267 & 0.2110 & 0.532 & & \\
\hline $\bar{\sigma}_{\text {quarter }}$ & 0.2738 & 0.2822 & -0.1350 & -0.0091 & 1.0000 & \\
$\bar{\sigma}_{\text {annual }}$ & 0.2307 & 0.2618 & 0.1182 & -0.0096 & 0.7440 & 1.0000 \\
\hline \hline
\end{tabular}




\section{Table 9: Understanding the Dynamics of Leverage for Survived Firms}

This table reports the cross-sectional regression results of Models II, III, and IV. The data set contains 4955 firms and 4766 firms when using book leverage and market leverage, respectively, from 1965 to 2006. $\bar{l}, \bar{\rho}$, and $\bar{\sigma}^{2}$ are firm's long-term mean leverage, persistence parameter from and $A R(1)$ model, and the residual mean square from the same $A R(1)$ model, respectively. Standard Deviation is in parentheses; $(*)$ denotes estimates that are significant at $95 \%$ confidence level. These standard errors are White's HAC. Variable definition can be found in the Appendix.

\begin{tabular}{|c|c|c|c|c|c|c|}
\hline \multirow[b]{2}{*}{ Variable } & \multicolumn{3}{|c|}{ Book leverage } & \multicolumn{3}{|c|}{ Market leverage } \\
\hline & $l$ & $\bar{\rho}$ & $\bar{\sigma}^{2}$ & $l$ & $\bar{\rho}$ & $\bar{\sigma}^{2}$ \\
\hline & \multicolumn{6}{|c|}{ Quarterly leverage } \\
\hline \multirow[t]{2}{*}{$\ln$ (Sales) } & $-0.0345^{*}$ & -0.0087 & $-0.0028^{*}$ & $-0.0148^{*}$ & -0.0035 & 0.0010 \\
\hline & 58) & $(.0049)$ & $(.0009)$ & $(.0064)$ & $(.0047)$ & $(.0009)$ \\
\hline \multirow[t]{2}{*}{ Book/Market } & $-0.0150^{*}$ & -0.0022 & 0.0010 & $-0.0971^{*}$ & -0.0050 & $-0.0116^{*}$ \\
\hline & $(.0036)$ & $(.0035)$ & $(.0008)$ & $(.0075)$ & $(.0050)$ & $(.0009)$ \\
\hline \multirow[t]{2}{*}{$\mathrm{ROA}$} & -0.0222 & $0.1158^{*}$ & $-0.0306^{*}$ & $-0.1840^{*}$ & $0.1235^{*}$ & $-0.0387^{*}$ \\
\hline & $(.0266)$ & $(.0335)$ & $(.0061)$ & $(.0373)$ & $(.0361)$ & $(.0069)$ \\
\hline \multirow[t]{2}{*}{ Tangible Assets } & $0.0587^{*}$ & $0.0845^{*}$ & $-0.0112^{*}$ & $0.0477^{*}$ & $0.0897^{*}$ & $-0.0102^{*}$ \\
\hline & $(.0190)$ & $(.0177)$ & $(.0028)$ & $(.0202)$ & $(.0147)$ & $(.0027)$ \\
\hline \multirow[t]{2}{*}{$\ln$ (Total Assets) } & $0.0621^{*}$ & -0.0006 & $-0.0029^{*}$ & $0.0582^{*}$ & 0.0018 & $-0.0041^{*}$ \\
\hline & $(.0071)$ & $(.0062)$ & $(.0012)$ & $(.0080)$ & $(.0062)$ & $(.0011)$ \\
\hline \multirow[t]{2}{*}{$\ln (\mathrm{CF}$ Volatility $)$} & $-0.0228^{*}$ & $0.0135^{*}$ & $0.0037^{*}$ & $-0.0386^{*}$ & 0.0076 & 0.0006 \\
\hline & $(.0043)$ & $(.0044)$ & $(.0008)$ & $(.0056)$ & $(.0045)$ & $(.0008)$ \\
\hline \multirow[t]{2}{*}{ Dividend Dummy } & $-0.0210^{*}$ & -0.0103 & $-0.0073^{*}$ & $-0.0189^{*}$ & -0.0070 & $-0.0075^{*}$ \\
\hline & $(.0077)$ & $(.0090)$ & $(.0013)$ & $(.0094)$ & $(.0081)$ & $(.0014)$ \\
\hline \multirow[t]{2}{*}{ Industry Median } & $0.3474^{*}$ & -0.0722 & 0.0038 & $0.4450^{*}$ & -0.0408 & 0.0024 \\
\hline & $(.0450)$ & $(.0470)$ & $(.0073)$ & $(.0331)$ & $(.0275)$ & $(.0047)$ \\
\hline \multirow[t]{2}{*}{ Adjusted $R^{2}$} & 0.1590 & 0.0380 & 0.1740 & 0.3420 & 0.0500 & 0.1950 \\
\hline & \multicolumn{6}{|c|}{ Annual Leverage } \\
\hline \multirow[t]{2}{*}{$\ln$ (Sales) } & $-0.0374^{*}$ & -0.0060 & $-0.0067^{*}$ & $-0.0200^{*}$ & 0.0036 & 0.0005 \\
\hline & & & $(.0014)$ & $(.0063)$ & $(.0097)$ & $(.0015)$ \\
\hline \multirow[t]{2}{*}{ Book/Market } & $-0.0158^{*}$ & $-0.0221^{*}$ & 0.0025 & $-0.0982^{*}$ & $-0.0236^{*}$ & $-0.0191^{*}$ \\
\hline & $(.0037)$ & $(.0076)$ & $(.0015)$ & $(.0087)$ & $(.0110)$ & $(.0016)$ \\
\hline \multirow[t]{2}{*}{$\mathrm{ROA}$} & $-0.0531^{*}$ & $0.2346^{*}$ & $-0.0336^{*}$ & $-0.2392^{*}$ & $0.2718^{*}$ & $-0.0657^{*}$ \\
\hline & $(.0267)$ & $(.0705)$ & $(.0099)$ & $(.0378)$ & $(.0808)$ & $(.0138)$ \\
\hline \multirow[t]{2}{*}{ Tangible Assets } & $0.0722^{*}$ & 0.0413 & $-0.0086^{*}$ & $0.0609^{*}$ & $0.0682^{*}$ & -0.0080 \\
\hline & $(.0186)$ & $(.0298)$ & $(.0041)$ & $(.0198)$ & $(.0289)$ & $(.0045)$ \\
\hline \multirow[t]{2}{*}{$\ln$ (Total Assets) } & $0.0644^{*}$ & -0.0038 & $-0.0048^{*}$ & $0.0622^{*}$ & 0.0033 & $-0.0090^{*}$ \\
\hline & $(.0070)$ & $(.0120)$ & $(.0017)$ & $(.0078)$ & $(.0123)$ & $(.0019)$ \\
\hline \multirow[t]{2}{*}{$\ln (\mathrm{CF}$ Volatility) } & $-0.0230^{*}$ & 0.0151 & $0.0076^{*}$ & $-0.0387^{*}$ & -0.0017 & $0.0040^{*}$ \\
\hline & $(.0042)$ & & & $(.0054)$ & $(.0096)$ & $(.0015)$ \\
\hline \multirow[t]{2}{*}{ Dividend Dummy } & $-0.0264^{*}$ & $0.0853^{*}$ & $-0.0177^{*}$ & $-0.0293^{*}$ & $0.0964^{*}$ & $-0.0211^{*}$ \\
\hline & $(.0076)$ & $(.0163)$ & $(.0020)$ & $(.0092)$ & $(.0169)$ & $(.0023)$ \\
\hline \multirow[t]{2}{*}{ Industry Median } & $0.3691^{*}$ & $0.4100^{*}$ & $-0.0242^{*}$ & $0.4217^{*}$ & $0.3215^{*}$ & -0.0100 \\
\hline & $(.0445)$ & $(.0836)$ & $(.0111)$ & $(.0322)$ & $(.0528)$ & $(.0078)$ \\
\hline Adjusted $R^{2}$ & 0.1830 & 0.0990 & 0.2420 & 0.3560 & 0.1100 & 0.2110 \\
\hline
\end{tabular}




\section{Table 10: Comparison of Out-of-sample Prediction for Leverage}

This table reports the out-of-sample prediction measured by root-mean-squared-error for both book leverage and market leverage using different models. The data set contains 4955 firms and 4766 firms when using book leverage and market leverage, respectively, from 1965 to 2006 . We randomly select 500 firms as the holdout sample. The long-term mean parameter $\hat{\bar{l}}_{i}$ and the persistence parameter $\bar{\rho}_{i}$ are first estimated using an $A R(1)$ model for each individual firms in the rest of the sample. We then run cross-sectional regression of Models II and III to find the beta estimates. These beta estimates

are used to form the predicted parameters $\hat{\overline{l_{i}}}$, and $\hat{\bar{\rho}}_{i} . l_{t}$ and $\hat{l}_{t}$ are actual and predicted leverage, respectively. Standard Deviation is in parentheses; $\left({ }^{*}\right)$ denotes estimates that are significant at $95 \%$ confidence level.

\begin{tabular}{cl|cc|cc}
\hline \hline Model $\begin{array}{l}\text { Prediction } \\
\#\end{array}$ & Model & \multicolumn{2}{|c|}{ Book leverage } & \multicolumn{2}{c}{ Market leverage } \\
\cline { 3 - 6 }$(1)$ & $\hat{l}_{t+1}=l_{0}$ & Mean & Std & Mean & Std \\
\hline$(2)$ & $\hat{l}_{t+1}=(1-\hat{\rho}) \hat{\bar{l}}+\hat{\rho} l_{t}$ & 0.0739 & 0.0385 & 0.1006 & 0.0430 \\
$(3)$ & $\hat{l}_{t+1}=(1-\hat{\hat{\rho}}) \hat{\bar{l}}+\hat{\hat{\rho}} \hat{l}_{t}$ & 0.1457 & 0.0708 & 0.1847 & 0.0777 \\
$(4)$ & $\hat{l}_{t+1}=(1-\hat{\hat{\rho}})+\hat{\bar{l}}+\hat{\hat{\rho}} l_{t}$ & 0.0936 & 0.0447 & 0.1229 & 0.0477 \\
\hline & Difference & Mean & $t$ & Mean & $t$ \\
\hline \multirow{2}{*}{$(1)-(2)$} & 0.0852 & 25.289 & 0.1124 & 26.662 \\
& $(3)-(2)$ & $(.0034)$ & & $(.0042)$ & \\
& & 0.0718 & 28.596 & 0.0841 & 28.518 \\
& $(4)-(2)$ & $(.0025)$ & & $(.0029)$ & \\
& & 0.0197 & 19.321 & 0.0222 & 18.558 \\
& $(1)-(3)$ & $(.0010)$ & & $(.0012)$ & \\
& & 0.0133 & 3.6114 & 0.0283 & 6.3307 \\
& $(1)-(4)$ & $(.0037)$ & & $(.0045)$ & \\
& & 0.0654 & 19.478 & 0.0902 & 21.270 \\
& $(3)-(4)$ & $(.0034)$ & & $(.0042)$ & \\
& 0.0521 & 31.494 & 0.0619 & 30.990 \\
\hline \hline
\end{tabular}

